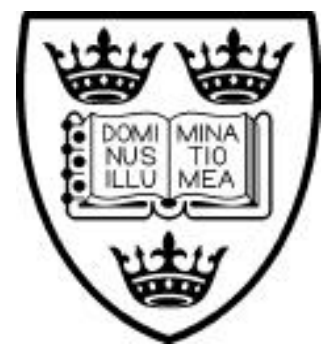

U N IVERS I TY OFOXFORD

Discussion Papers in

Economic and Social History

Number 21, December 1997

\title{
TIME AND WORK IN EIGHTEENTH-CENTURY LONDON
}

\author{
HANS-JOACHIM VOTH
}




\section{U NIVERS ITY OF O XFORD \\ Discussion Papers in Economic and Social History}

1 Hans-Joachim Voth and Tim Leunig, Did Smallpox Reduce Height? Stature and the Standard of Living in London, 1770-1873 (Nov. 1995)

2 Liam Brunt, Turning Water into Wine - New Methods of Calculating Farm Output and New Insights into Rising Crop Yields during the Agricultural Revolution (Dec. 1995)

3 Avner Offer, Between the Gift and the Market: the Economy of Regard (Jan. 1996)

4 Philip Grover, The Stroudwater Canal Company and Its Role in the Mechanisation of the Gloucestershire Woollen Industry, 1779-1840 (March 1996)

5 Paul A. David, Real Income and Economic Welfare Growth in the Early Republic or, Another Try at Getting the American Story Straight (March 1996)

6 Hans-Joachim Voth, How Long was the Working Day in London in the 1750s? Evidence from the Courtroom (April 1996)

7 James Foreman-Peck, 'Technological Lock-in' and the Power Source for the Motor Car (May 1996)

8 Hans-Joachim Voth, Labour Supply Decisions and Consumer Durables During the Industrial Revolution (June 1996)

9 Charles Feinstein, Conjectures and Contrivances: Economic Growth and the Standard of living in Britain During the Industrial Revolution (July 1996)

10 Wayne Graham, The Randlord's Bubble: South African Gold Mines and Stock Market Manipulation (August 1996)

11 Avner Offer, The American Automobile Frenzy of the 1950s (Dec. 1996)

12 David M. Engstrom, The Economic Determinants of Ethnic Segregation in Post-War Britain (Jan. 1997)

13 Norbert Paddags, The German Railways - The Economic and Political Feasibility of Fiscal Reforms During the Inflation of the Early 1920s (Feb. 1997)

14 Cristiano A. Ristuccia, 1935 Sanctions against Italy: Would Coal and Crude Oil have made a Difference? (March 1997)

15 Tom Nicholas, Businessmen and Land Purchase in Late Nineteenth Century England (April 1997)

16 Ed Butchart, Unemployment and Non-Employment in Interwar Britain (May 1997)

17 Ilana Krausman Ben-Amos. Human Bonding: Parents and their Offspring in Early Modern England (June 1997)

18 Dan H. Andersen and Hans-Joachim Voth, The Grapes of War: Neutrality and Mediterranean Shipping under the Danish Flag, 1750-1802 (Sept. 1997)

19 Liam Brunt, Nature or Nurture? Explaining English Wheat Yields in the Agricultural Revolution (Oct. 1997)

20 Paul A. David, Path Dependence and the Quest for Historical Economics: One More Chorus of the Ballad Of QWERTY (Nov. 1997)

21 Hans-Joachim Voth, Time and Work in Eighteenth Century London (Dec. 1997) 


\title{
TIME AND WORK IN EIGHTEENTH CENTURY LONDON
}

\author{
HANS-JOACHIM VOTH
}

DEPT OF ECONOMICS, STANFORD UNIVERSITY

\begin{abstract}
Witnesses' accounts are used to analyse changes in working hours between 1750 and 1800. Two findings stand out. The paper demonstrates that the information contained in witnesses' accounts allows us to reconstruct historical time-budgets, and provides extensive tests of the new method. It also emerges that the number of annual working hours changed rapidly between the middle and the end of the eighteenth century. Estimates of labour input are presented. These findings have important implications for the issue of total factor productivity during the Industrial Revolution.
\end{abstract}




\section{TIME AND WORK IN EIGHTEENTH CENTURY LONDON}

Did England work any harder during the Industrial Revolution? Marx said so, and so did E.P. Thompson, but until now, we have no way of knowing. Literary sources are difficult to interpret, wage books are few and hardly representative, and clergymen writing about the idleness of their flock did little to validate their complaints. Instead of using these dubious sources, more than 2,000 men and women from eighteenth century London give evidence in this study. They come from all strata of society and all age groups, and appear as witnesses before the Old Bailey to answer a simple question: 'What did you do at the time of the crime?' Each of them gives their name, profession, and main activity - not just at the time of the crime, but often before and after it as well. At all hours of the day, on all days of the year, these testimonies provide snapshots of everyday life - preserved by the scribes in the Old Bailey courtroom who took down verbatim reports of the proceedings in shorthand.

Sometime between 1750 and 1800, Londoners began to work longer - much longer. Annual working hours increased by at least one fifth. Yet dramatic change proceeded alongside considerable stability. The average working day by the end of the eighteenth century was very similar to the one fifty years earlier; there were simply many more of them. Starting and stopping work, and the time taken for break, barely changed at all. At the same time, Monday became a regular day of work, and most of the religious and political holidays that reduced the workyear in 1750 disappeared.

Some puzzles can be resolved if these findings can stand up to further scrutinity. We can explain why consumption was rising at the same time as real wages were falling - a seeming contradiction recently emphasized by De Vries. ${ }^{1}$ Output growth during the Industrial Revolution was driven more by additional labour than by capital accumulation, and there was no increase in the efficiency with which the economy combined factors of production. Also, it becomes clear at what price Georgian Britain succeeded in feeding its rapidly growing population while, at the same time, it was fighting the wars with France and sustaining industrial development - a very considerable increase in work intensity.

1 De Vries 1993, 1994. 


\section{WORKING HOURS DURING THE INDUSTRIAL REVOLUTION}

It is part of conventional wisdom about the Industrial Revolution that workers were toiling longer by 1850 than they had done a century earlier. ${ }^{2}$ The most prominent statement was made by E.P. Thompson in his path breaking article 'Time, Work-Discipline, and Industrial Capitalism'. He argued that 'Saint Monday' (the practice of taking Monday off to recover from the weekend) was universally observed until the beginning of the nineteenth century. ${ }^{3}$ Once it began to disappear under the impact of the factory system, total workloads began to rise rapidly. In addition to the increase in labour input, work discipline increased sharply. ${ }^{4}$ 'Pre-industrial work' was characterized by irregularity. The allegedly slow pace of work on Tuesdays and Wednesdays is said to have gathered pace gradually during the course of the week, culminating in a frenetic rush at the end of the week to complete work. The Industrial Revolution thus transformed work patterns that were irregular and often proceeded at a leisurely pace into the iron discipline of the $19^{\text {th }}$ century cotton mills.

The importance of holy days in England before and during the Industrial Revolution has been a matter of discussion for some time. ${ }^{5}$ Freudenberger and Cummins added another aspect to the the issue of labour intensification when they argued that the observance of holy days was sharply reduced during the eighteenth century. ${ }^{6}$ The basis of their contention is a list of holy days contained in a handbook published by J. Millan in 1749. ${ }^{7}$ He gives 46 fixed days on which work at the Exchequer and other government offices ceased. Later, during the second half of the century, the observation of these holy days is said to have slowly vanished. Consequently, Freudenberger and Cummins argue, annual labour input possibly increased from less than 3,000 to more than 4,000 hours per adult male between 1750 and $1800{ }^{8}$ The cause of this rise in labour input was increased availability of food. As nutrition became more plentiful, people had less of an incentive to save on energy by maximizing the days of idleness. Thus, old feastdays gradually began to fall into disuse. More recently, De Vries has argued that working hours must have been rising rapidly in all of Europe since the increased standards of consumption cannot be explained by the course of real wages. An 'Industrious Revolution', giving rise to a maximum 307-day working year, must have been responsible for much of the wealth found in probate inventories. ${ }^{9}$

Unfortunately, the empirical basis for these views is weak. Thompson largely relies on literary sources. As many critics have argued, these are difficult to interpret as well as unrepresentative. ${ }^{10}$ Freudenberger and Cummins point to holy days mentioned in contemporary calendars. However, knowing that a day was officially recorded as a holy day is not the same as knowing that it was a day off. Even De Vries's elegant argument relies on indirect evidence of an increase in working time. Reasonably accurate estimates only become

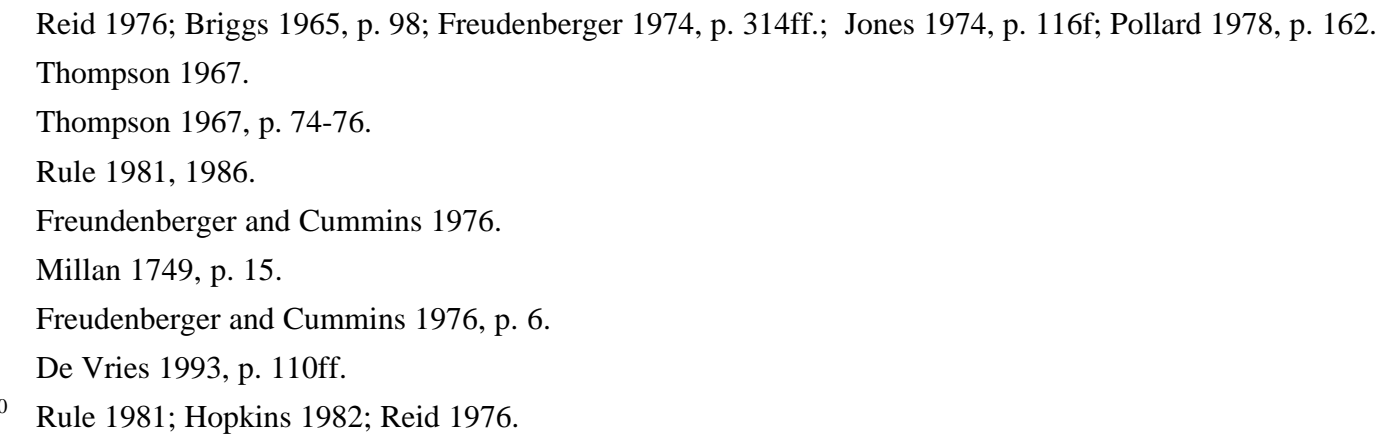


available from the 1850s. ${ }^{11}$ The verdict in the profession is unanimous - Crafts commented on the substantial body of literature that suggests an increase in the number of working hours per year that ' $[\mathrm{m}]$ easurement of this supposition has never been adequately accomplished...'. ${ }^{12}$ Mokyr concurs: ${ }^{13}$ 'We simply do not know with any precision how many hours were worked in Britain before the Industrial Revolution, in either agricultural or non-agricultural occupations.' The following section describes a method that is designed to fill this void in the historical record.

\section{COUGH PILLS AND THE LAW: DATA AND METHOD}

The 'Proceedings of the Sessions of the Peace, and Oyer and Terminer for the City of London and County of Middlesex' are a colourful source for modern historians. They came into existence as a precursor of the modern 'yellow press'. Interest in sex and crime has always been buoyant, and it was in the second half of the seventeenth century that entrepreneurs began to print reports about the proceedings at the Old Bailey in order to satisfy this demand. From the 1680s onwards, the city of London established some oversight over this publication, which received an official imprimatur. ${ }^{14}$

After 1729, the newspaper format was dropped, and the proceedings began to appear in quarto format. While the publication as a whole became much more respectable, it still contained advertisements for anything from cough pills to remedies against syphilis. During the 1720 s, verbatim reporting was introduced. ${ }^{15}$ For our purposes, the reports from the Old Bailey become truly useful after 1748. It was in this year that Thomas Gurney began to take down the proceedings in shorthand. He and his son should continue to act as scribes for the next 35 years. While the publisher changed with considerable frequency, ${ }^{16}$ the reports from the courtroom maintain a high degree of precision and detail.

Data collection was carried out for two periods, 1749/63 and 1799/1803. ${ }^{17}$ A total of 7,650 court cases were evaluated, leading to a little over 2,000 observations. ${ }^{18}$ In the majority of cases, a lack of information either on the time of the crime or the witness led to the exclusion of a case from the dataset. For obvious reasons, information from the accused was not included. The scarcity of sufficient information was more pronounced for the earlier period, when data collection had to be carried out on records from 14 years to collect a dataset of sufficient size. In sixty-two cases, witnesses' accounts were ruled not to be admissible evidence before the court, and were consequently excluded - even if the lie did not pertain to time-use information. ${ }^{19}$ It is likely that some inaccuracies, even gross

11 Matthews, Feinstein, Oddling-Smee 1982; Maddison 1991.

12 Crafts 1985 , p. 82.

13 Mokyr 1985, p. 32.

14 Harris 1984, p. 9.

15 Ibid., p. 10f.

16 Ibid., p. 11f.

17 When a trial was held in 1800 for a crime committed in 1799, these observations were also entered. The same applies to $1749 / 50$.

18 The number of occasions when a single trial led to more than one entry was small.

19 A typical example reads like this: 'The jury declared they believed but very little of what Tindal had sworn; and not a word that Woolf, Trueman, and Pretyman had sworn: And desiring that the three last might be committed for perjury, they were committed accordingly.' Old Bailey Sessions Papers, Case No. 73, 1756. 
misrepresentations, went unnoticed before the court. In so far as they relate to time-use, this is not necessarily a grave problem: the witness was obviously able to invent a probable, possibly even a typical activity pattern.

\section{Sociological techniques}

Sociological studies have used a large number of different methods to measure time-budgets. Only three provide reliable results:

1. Electronic pagers. Individuals participating in the study are asked to carry one of these electronic devices with them. At random intervals, these will sound a beep, and the test participant notes the activity he or she is engaged in at that moment.

2. Diaries. Participants are asked to fill in their activities while they are actually engaged in them. This is the most widely used method.

3. Random hour recall. Individuals are asked to provide a thorough description of their activities for a randomly chosen hour of the previous day.

Time-use sociologists have determined that the random-hour method is clearly superior to all others. ${ }^{20}$ This is fortunate for the project of reconstituting a historical time budget: the randomhour method - broadly defined - can be replicated using archival sources, whereas the diary method cannot be applied for obvious reasons. ${ }^{21}$ Witnesses' accounts in judicial records give the same type of information normally recorded in random-hour recall studies. Witnesses very often not only mention their occupation and sex (and, in a substantially lower number of cases, age and address), but also report what they were doing at the time of the crime, at the time when they last saw the victim, or when they observed the perpetrator trying to escape. This constitutes almost an exact parallel to the most reliable of present-day sociological techniques. 22

Crimes are also committed on all days of the week, during all seasons of the year. All hours of the day are present in the sample. Some caveats nonetheless apply. The period between the relevant activity and the time when it needs to be recollected is considerably longer than in most sociological studies. I will later demonstrate that this is of little consequence. ${ }^{23}$ Sample selection bias is a more serious challenge. Those witnessing a crime may be reluctant to come forward to testify for a variety of reasons. The crucial question is whether the part of the population that is willing to speak in court is a biased sample due to the 'selection procedure'. Those trying to evade the duties of a witness may - as in the case of present-day sociological studies - be the more active part of the population. But since most accounts of crimes contain descriptions (by other witnesses, and, more often, customs officers,

20 Juster and Stafford 1991.

21 Admittedly, some diaries (like the ones of Samuel Pepys) contain extensive information on time-use. Yet the number of such texts is so severely limited that reconstituting a time-budget on this basis would be a perilous undertaking.

22 Furthermore, this information also fulfills another requirement established by time-use research: 'The only way in which reliable data on time allocation have been obtained is [from] a sample of individuals in a population and organised in such a way as to provide a probability sample of all types of days and of the different seasons of the year.' Juster, Stafford 1991, p. 473.

23 'Of the other quality variables, interview mode is never statistically significant, and length of the recall period is significant ... in only one equation.' Juster 1986, p. 394. 
watchmen and the like) of all the people present at the locus of the crime, it is possible to ascertain whether systematic bias can be expected.

In general, there is little evidence to suggest that witnesses attempted to create an ideal image of social respectability before the court. While the language of the court is often of an elevated nature (sex is always referred to as 'carnal intimacy'), those called to give evidence show few inhibitions, relating freely that they 'went awhoring' or gave someone 'a good licking' ${ }^{24}$

\section{IN THE SWEAT OF THEIR BROWS - TIME USE 1750-1800}

What do the Old Bailey witnesses tell us about time-use in eighteenth-century London? I begin by describing time-use during the day during two periods - 1749-63 and 1799-1803. The times of starting and stopping work as well as the hours of sleep are examined. I then analyse patterns of time-use during the week and the year. Comparisons of the two periods are made and an estimate of the length of the working year is presented.

\section{Time-use during the day}

The average witness during the 1750s rose at 6:10. A total of 59 individuals gave evidence before the court about their time of rising in the morning. The earliest riser in our sample is a publican who gets up at 2:00 on 4 July 1756 to go 'a mowing' $\cdot{ }^{25}$ No individual rose later than a domestic servant, who, on Sunday, 14 March 1759 lies in bed until 10:30 a.m. These extremes were highly unusual. Half of our sample rose between 5 and 7 a.m. To see that the vast majority of Londoners rose at a time much closer to our estimate of the mean, consider the cumulative frequency plot in figure 1.

\section{Rising in the morning}

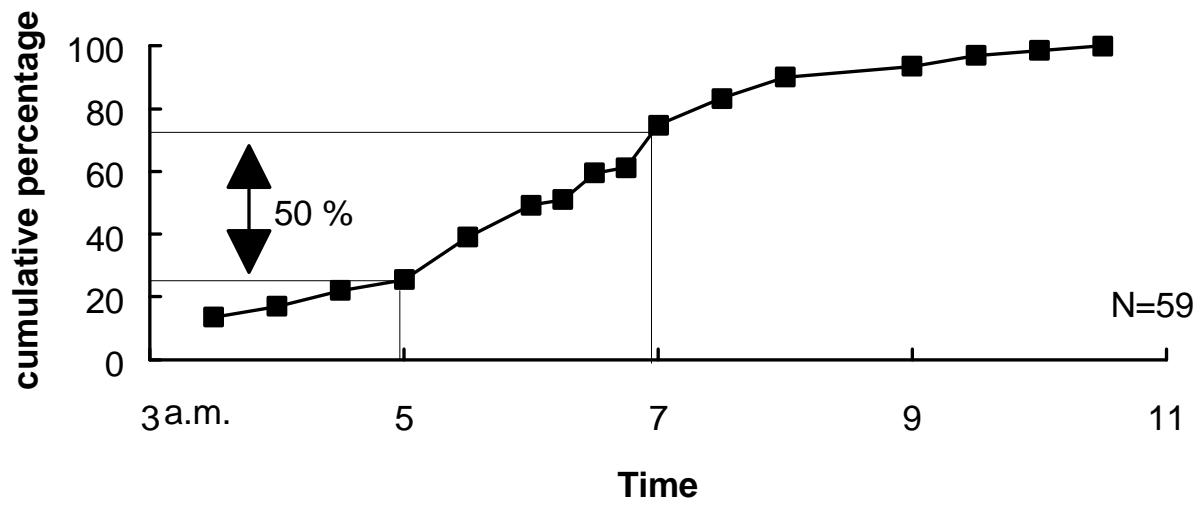

Figure 1

24 Old Bailey Sessions Papers, Case No. 101, 1752.
25 Old Bailey Sessions Papers, Case No. 300. 1756. 
Given the wide dispersion in our sample as well as the limited sample size, the $95 \%$ confidence interval is quite wide, extending from 5:41 to 6:39. In addition, a further problem arises. Some statements by witnesses are not very precise. While most give the exact time of rising in the morning, 25 percent are only precise to within one hour. The overall impact, however, is quite limited - we have to widen the confidence interval by another five minutes on both sides. ${ }^{26}$

Work during the 1750s began shortly before 7:00. On average, the 44 witnesses started work at 6:50. Before 6:00, only a quarter of the individuals who gave evidence were already at their workplaces. The vast majority of witnesses started work between 6:00 and 7:00. Such an early start to the working day was not everyone's lot - in 1759, we find a stockbroker starting work at 10:00. ${ }^{27}$ Work stopped at 18:50 on average. This average also includes the many unskilled labourers who were employed on an occasional basis and often finished their daily work during the early afternoon. Skilled craftsmen, apprentices and masters often worked until 7 p.m. or 8 p.m. ${ }^{28}$

On average, the witnesses giving evidence before the Old Bailey went to bed at around 11 p.m. The statistical average is 22:50, and with a standard error of the mean of less than ten minutes, we can be $95 \%$ certain that the mean for the underlying population was between $22: 30$ and 23:10. One quarter $(26 \%)$ of all cases give the timing to within one hour. If we again assume that all of these individuals erred by a maximum of 20 minutes on one side, then we have to add 5 minutes to the confidence interval. We can state with considerable certainty that, on average, our study subjects retired to bed between 22:25 and 23:15.

Fifty years later, we find 34 individuals reporting their time of rising in the morning 5:56 on average. Given the wide confidence interval, we cannot claim that witnesses rose much earlier than their ancestors during the middle of the eigtheenth century. Work began at half past six now (6:33 on average), a little earlier than in the first sample. Also, 44 witnesses reported their time of stopping work before the court. The average time is 19:07, but because of the large variation and the relatively small sample, we calculate that the $95 \%$ confidence interval extends from 18:30 to 19:44. Londoners in our sample were not only early risers, they also went to bed rather late. Unsurprisingly, the latest bedtimes seem to have been the result of important social events: On December $24^{\text {th }}, 1800$, a journeyman tailor is being entertained and is dancing at his master's house, until he finally goes home at 4:00 a.m. ${ }^{29}$ The earliest time

26 The mean for the relatively imprecise observations is 6:38. Without these observations, the overall mean would have been 6 a.m. Let us assume that all of these individuals had been much closer to the lower bound of the range than to the upper bound: every time a witnesses claimed to have risen between 3 and 4 , he or she would have left bed at 3:10 (instead of the 3:30 that we assigned). Every single one of our observations in this category would then have introduced an error of 20 minutes into the calculation of the mean. It seems inherently unlikely that they would have all erred on the same side. Even if this had been the case, the effect on our estimate of the overall mean is nonetheless small. If the less accurate statements were all 'off' by 20 minutes in the same direction, then a maximum bias of 5 minutes would have been introduced $\left(0.25^{*} 20\right)$. If such a systematic form of imprecision existed, we would have to revise the average to 6:05. Similarly, if every single witness in this category had erred on the high side, the upper bound would be 6:15. The overall confidence interval therefore has to be widened by five minutes on either side. Compared to the error bands arising from the statistical properties of our data, the maximum inaccuracy introduced by using midpoint estimates is small.

27 Old Bailey Sessions Papers, Case No. 317, 1759.

28 This very similar to the figures given in contemporary accounts of working hours. Cf. Campbell 1747, p. $330 \mathrm{ff}$.

29 Old Bailey Sessions Papers, Case No. 117, 1800. It would be perilous to claim that this was a "normal" day of the year, and that behaviour reflected everyday regularities. This observation was consequently discarded in the subsequent calculation of the average as well as of upper and lower bounds. 
recorded in our sample stems from a milkwoman, who went to bed at 21:00. ${ }^{30}$ On average, slightly later bedtimes prevailed, with the mean of our observations being 23:21.

\section{Mondays and Holy Days}

The witnesses giving evidence before the Old Bailey during the 1750 s were very likely to take Sunday and Monday off, and to work on Saturdays. I regressed a dummy variable indicating if a person worked on a dummy for the day of the week. ${ }^{31}$ The use of a logit regression is necessary since the dependent variable is dichotomous. ${ }^{32}$ Results were as follows:

Table 1: Logit Regressions (dep. var.: individuals engaged in work, 1749-63)

\begin{tabular}{lcccc}
\hline \multicolumn{1}{c}{ Weekday } & $B$ & Wald & $\Delta$ Odds Ratio & Significance \\
\hline Sunday & -0.66 & 4.24 & $0.52^{* *}$ & 0.039 \\
Monday & -0.51 & 5.14 & $0.59 * *$ & 0.023 \\
Tuesday & -0.11 & 0.23 & 0.89 & 0.62 \\
Wednesday & 0.23 & 1.32 & 1.26 & 0.25 \\
Thursday & 0.15 & 0.55 & 1.17 & 0.46 \\
Friday & 0.07 & 1.07 & 1.07 & 0.74 \\
Saturday & 0.43 & 4.53 & $1.54 * *$ & 0.033 \\
\hline
\end{tabular}

Note: *,** indicates significance at the 90 and 95 percent levels, respectively.

The Wald-test has a $\chi^{2}$ distribution; significance levels according to Hauck and Donner 1977, p. 851ff.

Only three days of the week are significantly different from all others - Saturday, Sunday and Monday. Sunday and Monday are very clearly days of rest, showing large reductions in the probability of finding people at work. Saturdays record an above-average incidence of work. ${ }^{33}$

Repeating the exercise for the beginning of the $19^{\text {th }}$ century yields a different result.

Table 2: Logistic Regressions (dep. var.: individuals engaged in work, 1749-63)

\begin{tabular}{lcccc}
\hline \multicolumn{1}{c}{ Weekday } & $B$ & Wald & Odds Ratio & Significance \\
\hline Sunday & -0.64 & 23.1 & $0.53^{* *}$ & 0.04 \\
Monday & -0.21 & 0.99 & 0.81 & 0.32 \\
Tuesday & 0.38 & 3.7 & $1.45^{*}$ & 0.055 \\
Wednesday & 0.12 & 0.33 & 1.13 & 0.56 \\
Thursday & -0.11 & 0.28 & 0.89 & 0.59 \\
Friday & 0.19 & 0.89 & 1.22 & 0.35 \\
Saturday & 0.27 & 1.95 & 1.31 & 0.16 \\
\hline
\end{tabular}

Note: $* * *$ indicates significance at the 90 and 95 percent levels, respectively.

30 Old Bailey Sessions Papers, Case No. 597, 1802.

31 Hardy 1993.

32 Demaris 1992.

33 The definition of work used was rather restrictive - I only used information on those witnesses who reported being at work, and not those starting or stopping work. Results are not sensitive to such questions of definition. Additional results are available from the author. 
Sunday is still clearly a day of rest, but the prominent position of both Mondays and Saturdays has vanished. There is still a slight reduction in the probability of observing witnesses at work on a Monday, but it is not significant at any of the customary confidence levels. Surprisingly, Tuesdays now appear to record a slightly higher incidence of work, whereas Saturdays no longer record an unusual incidence of work.

Similar changes can be observed in the case of old religious and political holy days. I examined whether our witnesses were less likely to work on feast days (as recorded in a contemporary calendar by Millan). ${ }^{34}$

34 Millan 1749. 
Table 3: Logistic Regressions - Work on Holy Days

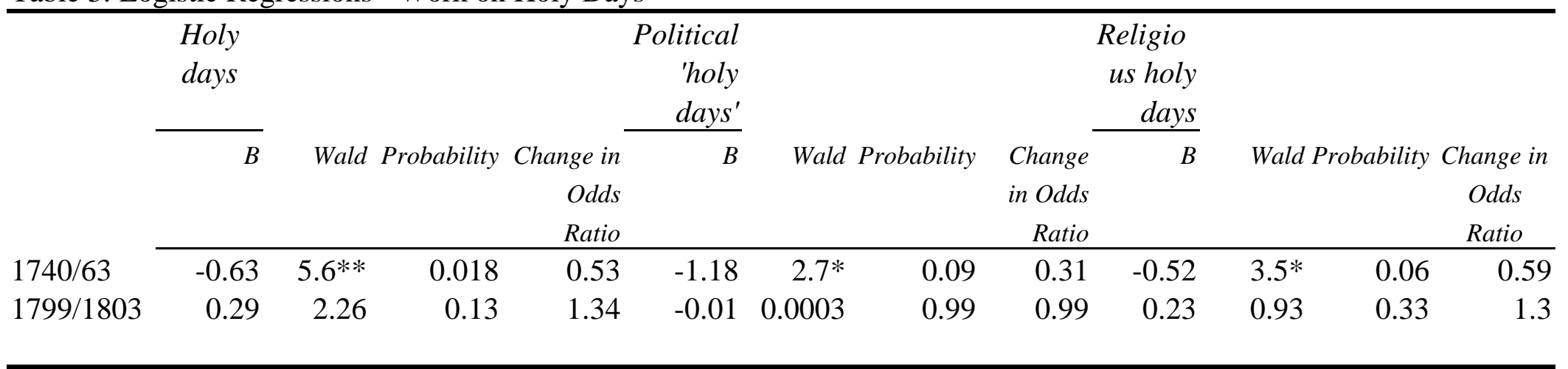

Note: $*, * *$ indicates significance at the 90 and 95 percent levels, respectively. 
On holy days during the 1750 s, we observe a strong and significant reduction in the probability of witnesses working. This goes for both political and religious holy days, with the effect being a little more pronounced for political festivals. Fifty years later, there is a slight tendency for witnesses to work more often on holydays, but the effect cannot be estimated with great accuracy. Only in the case of political feast days is there a reduction of the probability of observing witnesses in paid work, but it is very small and not significant according to the Wald-statistic.

\section{Change over time}

The basic structure of life remained largely unchanged during the second half of the eigtheenth century. The timing of main activities during the day shows barely any differences. Hours of sleep were shorter towards the beginning of the nineteenth century than during the middle of the eighteenth century, but the difference is not significant. While sleep averaged 7 hours and 27 minutes for 1750/63, this figure had fallen to 6 hours and 35 minutes in 1800/03. It must be stressed that the difference is not statistically significant at the customary $90 \%$ and $95 \%$ levels. Of the 52 minute difference between the averages, 24 were caused by people rising earlier, while 28 minutes of rest were lost due to later bedtimes.

Hours of work during the day were also largely static. While people in the Old Bailey Sessions Papers on average started work at 6:45 a.m. during the 1750s and early 1760s, the respective figure for $1800 / 03$ is $6: 33$ a.m. The difference is equally small between the times of stopping work. Work activities ended at 6:48 p.m. in the 1750s; fifty years later, the average working day extended to 7:06 p.m. Again, these differences are not statistically significant. Unless changes in the duration of meals were dramatic, the best guess estimate for daily working hours for both periods is eleven hours. ${ }^{35}$ Note that our estimate for daily working hours is in close agreement with the data published in Campbell's London Tradesman from 1747. Campbell's guide, which describes in some detail the various professions found in mideighteenth century London, their work-practices and economic situation, also contains a long list of London trades' 'hours of working' ${ }^{36}$ The average starting time for the 182 professions contained in his work is 6:08 a.m. This does not agree perfectly with our estimate; it is nonetheless easily within the $95 \%$ confidence interval. The slight tendency towards later hours in our sample is probably due to differences in sample composition - Campbell restricts himself to artisans, whereas our sample also contains occasional labourers and others who were more likely to start work later in the day.

In marked contrast to the unchanging pattern of daily life, time allocation both during the week and during the year exhibits radical change. Our dataset allows us to test both the Thompson and the Freudenberger/Cummins-hypothesis rigorously and on a large empirical basis. As discussed above, in the 1750 s the probability of observing an individual at work is sharply reduced on Mondays. Indeed, Monday was virtually identical with Sunday in this regard. This strongly suggests that, during the middle of the eighteenth century, Monday was a

\footnotetext{
35 For both periods, I checked if those starting work came from the same occupations as those stopping work. While this is an imperfect test for sample composition, it is the only one that can readily be performed. $\chi^{2}$-tests fail to reject the null of no significant difference in both cases.

36 Campbell 1747, p. 330ff.
} 
day off. Witnesses' time-use in 1800/03 was quite different. While the probability of observing individuals engaged in work activities on a Monday is again smaller than on average, logistic regressions demonstrate that this effect is not statistically significant. With respect to patterns of paid work, Monday does not differ from other days of the week. On the basis of the findings inferred from the probability of observing individuals engaged in work, there is no conclusive evidence to suggest that workers enjoyed an extended weekend through the custom of 'Saint Monday' as late as 1800/03, let alone that the practice was widely observed until the middle of the nineteenth century. It therefore seems sensible to conclude that 'Saint Monday' declined rapidly during the second half of the eighteenth century, and that it had all but disappeared by the turn of the century.

A similarly large change occurred on public and religious holidays. Our dataset was used to test the Freudenberger/Cummins interpretation empirically. As the preceding section demonstrated, the probability of observing people in paid employment on holidays was sharply reduced. The impact was large, suggesting that work was as rare on a holy day as on a Sunday (or on 'Saint Monday'). The same is not true in 1800/03. Here, the change in the odds ratio from logit models suggests an (insignificant) positive effect. Holy days no longer influenced everyday patterns of labour and leisure in London at the turn of the century.

How long, then, was the working year during the eighteenth century? I estimated that the average working day was 11 hours long, and that, in the 1750s, Sundays and Mondays as well as the 53 holy days (46 listed by Millan plus seven on Christmas, Easter and Whitsun) were days off. ${ }^{37}$ This leaves 208 working days per year. If our conclusions about changing time-budgets during the second half of the eighteenth century are correct, this implies that there were 2,288 hours of work/year. ${ }^{38}$ This result represents a lower bound. We assume that, since the probability of observing individuals on Mondays, Sundays and holy days is sharply reduced, these are not 'normal working days'. Yet the changes in the odds ratio only show a reduction of roughly $40-50 \%$ on these days compared with all the others. These 'other days', however, contain (if we are interested in Mondays, say), Sundays and weekdays which were holy days. Consequently, the relative reduction in the probability is understated. Compared to the average working day, it is more accurate to assume that Mondays, Sundays and holy days registered a 70 percent lower probability of observing individuals in paid work. ${ }^{39}$ It seems likely that the remaining 30 percent simply point to individuals who are not employed in professions keeping 'normal hours', such as inn-keepers, coach drivers or chairmen. Treating the remaining 30 percent as if they were still engaged in normal work activities gives an upper-bound estimate for working hours in the year (equivalent to 2631 hours).

For $1800 / 03$, the calculation is more straightforward. There is little evidence to suggest that 'Saint Monday' was still the occasion of much absenteeism. Holy days no longer influenced

37 The difference between starting and stopping work was exactly 12 hours. Based on the timing of lunch and breakfast, I deducted 1.5 hours for mealtimes (further details available from the author).

38 Allowing two days for Christmas and four days for Easter. Anecdotal evidence on working patterns during the eighteenth century has always stressed the importance of fluctuating short-term employment (e.g. on the docks). Cf. Schwarz 1992, p. 108ff. Since those employed short-term are included in my estimates of the time when work started and stopped, this factor has been taken into consideration. The underlying assumption is that occasional labourers were as likely to appear as witnesses (given their share in the total labour force) as member of other professions.

39 The change in the log odds ratio for these days is roughly 0.5 . For a Monday, this reduction applies vis-a-vis an 'average day' containing Sundays and holy days. They present approximately 25 percent of the year. Since on these days, too, the chance of observing an individual in paid work is only 0.5 of what it is on all the other days, the probability for Monday compared to average working days is closer to 30 percent $(1-[98 / 365]) *(0.5)$. 
work activities. Work ceased on 52 Sundays in the year, plus 7 days at Christmas, Easter and Whitsun. This implies a working year of 306 days; combined with the 11 hour working day, this suggests 3,366 hours of work per year. If we again assume that the 70 percent lower probability of observing individuals on Sundays indicates that $30 \%$ of the population regularly worked on this day, then the upper bound estimate for 1800/03 becomes 3,538 hours/year. The difference between both upper bound calculations is 907 hours; for the two lower bounds, the difference is 1,078 hours/year. The extent of the upward movement is therefore not very sensitive to assumptions about work on Mondays, holidays and Sundays - the change between 1760 and 1800 in the upper bound scenario is $118 \%$ of the change in the lower bound scenario. Change over time is therefore much easier to infer from our data than absolute levels.

Table 4: Working hours/year, 1760 and 1800

\begin{tabular}{lccc}
\hline & 1760 & 1800 & $\Delta$ \\
\cline { 2 - 4 } Lower Bound & 2,288 & 3,366 & 1,078 \\
Upper Bound & 2,631 & 3,538 & 907 \\
\hline
\end{tabular}

So far, I have ignored changes in the occupational composition of the labour force. Where we have evidence on agricultural employment, it shows markedly higher probabilities of employment on Sundays, Mondays and holy days. The probability was roughly 0.6 of the average. The first question therefore has to be whether it is credible that the working year in agriculture was even longer than in the other professions. If our answer is yes, then we will have to adjust the change in annual labour input downwards. The percentage of the labour force employed in agriculture declined during the second half of the eighteenth century. Therefore, the shift out of one of the most labour-intensive sectors would have exerted a diminishing influence on the upward movement of working hours. If we believe that the working year in agriculture was roughly equivalent to that in other professions, then no further adjustments are needed.

Indirect evidence supports the notion that working hours were particularly long in agriculture. During the industrialisation process, the reallocation of labour from the primary to the secondary sector is normally accompanied by low productivity in the former. In England, however, output per agriculturist was not very far below the level attained in other sectors. By 1800 , the sectoral productivity gap had almost disappeared (table 5).

Table 5: Productivity Gap in Agriculture

\begin{tabular}{lcccc}
\hline & 1700 & 1760 & 1800 & 1840 \\
\cline { 2 - 5 } $\begin{array}{l}\text { Percentage of Labour } \\
\text { Force in Primary Sector }\end{array}$ & 57.1 & 49.6 & 39.9 & 25.0 \\
$\begin{array}{l}\text { Percentage of Income in } \\
\text { Primary Sector }\end{array}$ & 37.4 & 37.5 & 36.1 & 24.9 \\
$\begin{array}{l}\text { Productivity Gap in the } \\
\text { Primary Sector (\% of } \\
\text { av.) }\end{array}$ & -34.5 & -24.4 & -9.5 & -0.004 \\
\hline
\end{tabular}

Source: $\quad$ Crafts 1985, table 3.6, p. 62f. 
The comparatively small (and rapidly disappearing) difference in productivity, and the ability of English agriculture to feed a rapidly growing population while employing an almost constant number of men, both lend indirect support to the hypothesis that labour input per member of the agricultural workforce was high.

Crafts's figures suggest a decline of 7.5 percent in the agricultural share of the labour force. In revising the previous estimates, we therefore have to take into account two additional factors: first, agriculture's special work rhythm raises the estimated labour input for 1760 . Second, the shift out of the primary sector acts as a countervailing force to the increase in the overall length of the working year. If we assume that outside the primary sector, Sundays, Mondays and holy days were 'days of idleness' and that $60 \%$ of the agricultural labour force worked on these days (during both periods), then the reallocation of workers reduced the rise in annual labour input by 340 hours/year. ${ }^{40}$ Combined with our lower bound estimates, we arrive at an average working year of 3,501 hours (figure 2). ${ }^{41}$ If we assume that $30 \%$ of the total labour force worked on the (extended) weekend and $60 \%$ did so in agriculture, the movement into the secondary and tertiary sectors would only have diminished labour input by 170 hours/year. Since our reduction by 170 hours/year is the smaller of the two (negative) adjustments we have to make, it is sensible to combine it with the upper bounds. The result is an estimated working year of 3605 hours (figure 3). ${ }^{42}$ The upper bound estimate is therefore only three percent higher than the lower bound estimate; the increase in annual workloads amounted to 585 to 738 hours. Given the limited precision of the underlying estm

Working Hours in England, 1750-1800 (Scenario A)

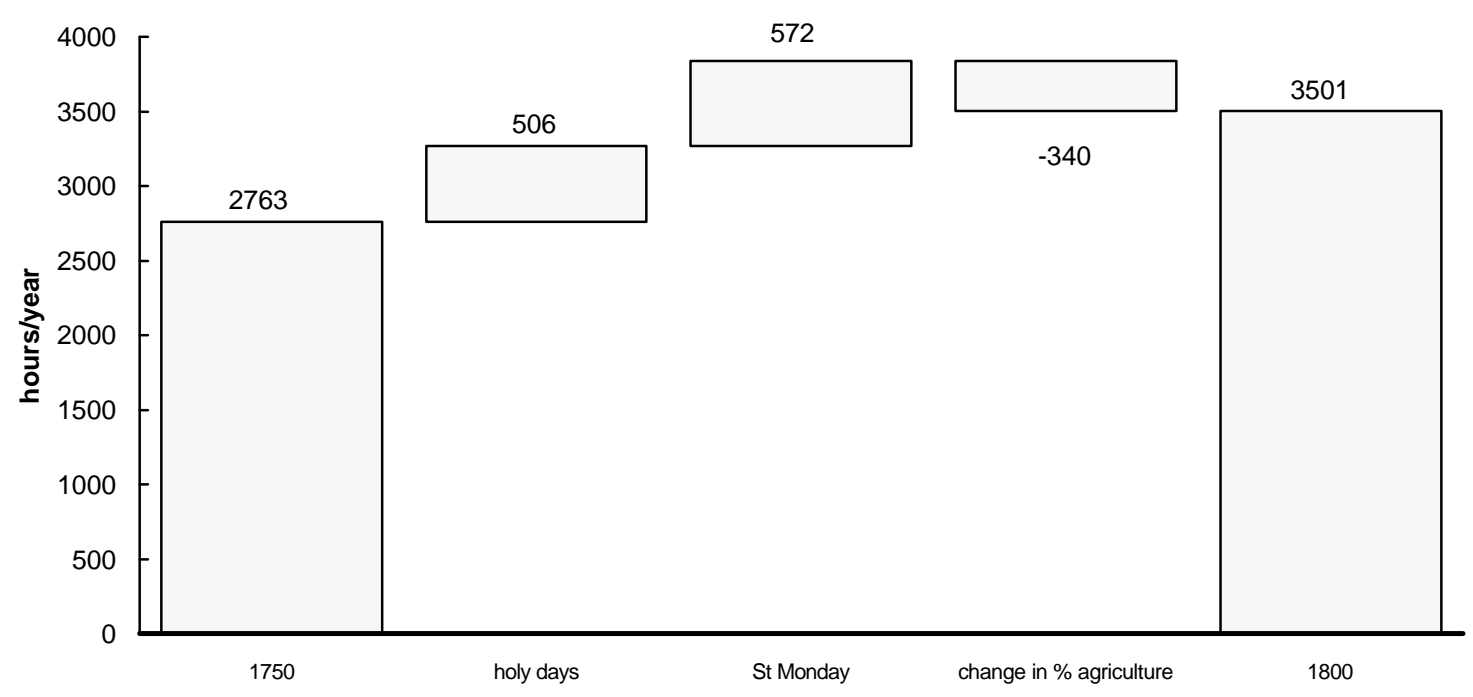

Figure 2

40 Future research will have to examine differences in time-use between pastural and arable areas.

41 Due to the new assumption about the working year in agriculture, the lower bound is now 2763 hours/year for the earlier period.

42 Incidentally, this figure lies in the same range as Phelps Brown's educated guess (3500-3750). Cf. Phelps Brown, Browne 1968, p. 487. 
Working Hours in England, 1750-1800 (Scenario B)

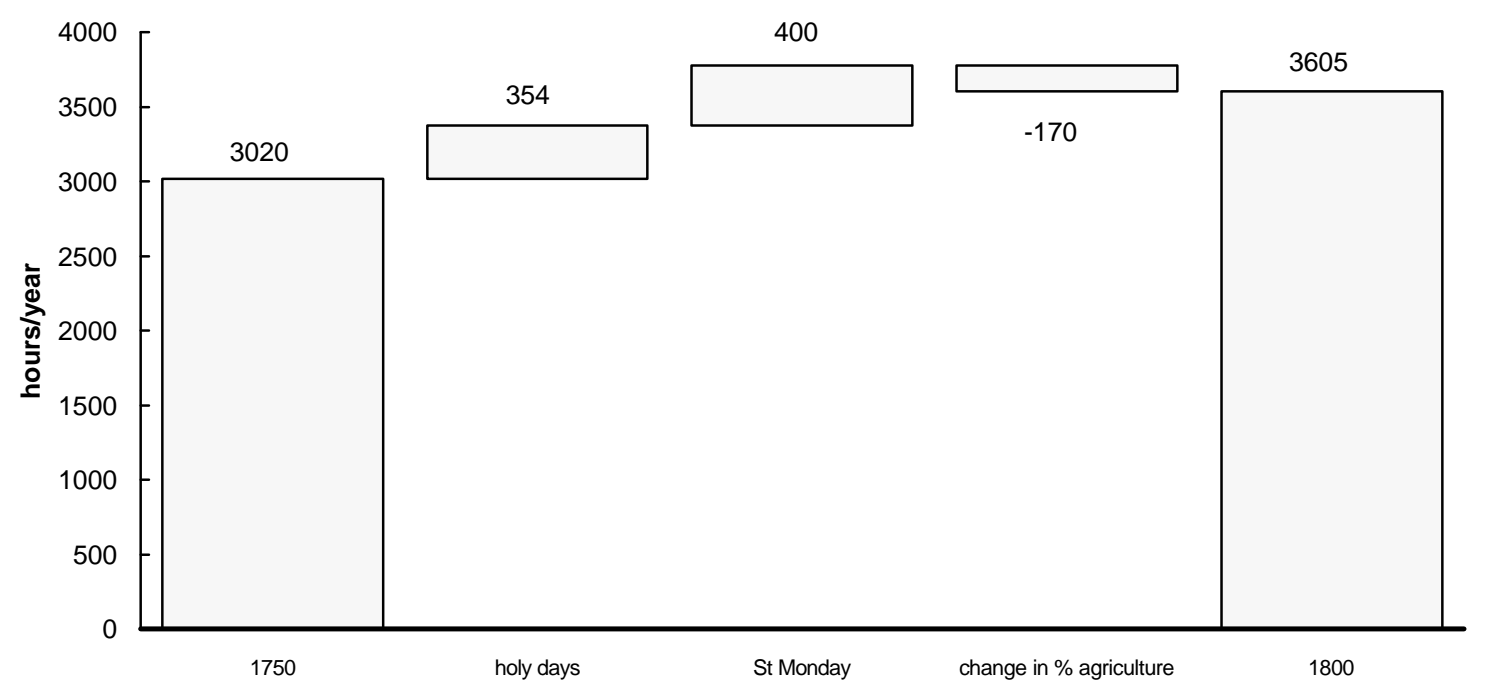

Figure 3

Labour input grew by 20 to 27 percent; the elimination of holy days and of Saint Monday alone would have boosted the length of the working year by 25 to 39 percent. The reduction caused by the reallocation of labour was equivalent to 6 to 12 percent of the starting level. ${ }^{43}$

How did working time change in the long-run? Presently, there are data on the changing number of working hours in the year for little more than the last century. ${ }^{44}$ While it must be emphazised that the precision of our estimates is considerably lower than the accuracy of more recent ones, and that our data largely refers to London, we can now provide a rough outline of the course of working hours since the Industrial Revolution. Figure 4 gives an overview:

43 Note that, because of our assumptions about the length of the working year in agriculture, the starting levels are different from the ones used in table 4.

44 Data came from Maddison 1991, table C.9, p. 270. The Maddison series is augmented in 1870 with the figure inferred from Bienefeld 1972, p. 111. MFO is the series in Matthews, Feinstein and Oddling-Smee 1982, table 3.11, p. 64. Differences are largely due to assumptions about vacations, sick leave etc., but the empirical basis of the MFO series appears to be more reliable. 
Working Hours in England, 1700-1989

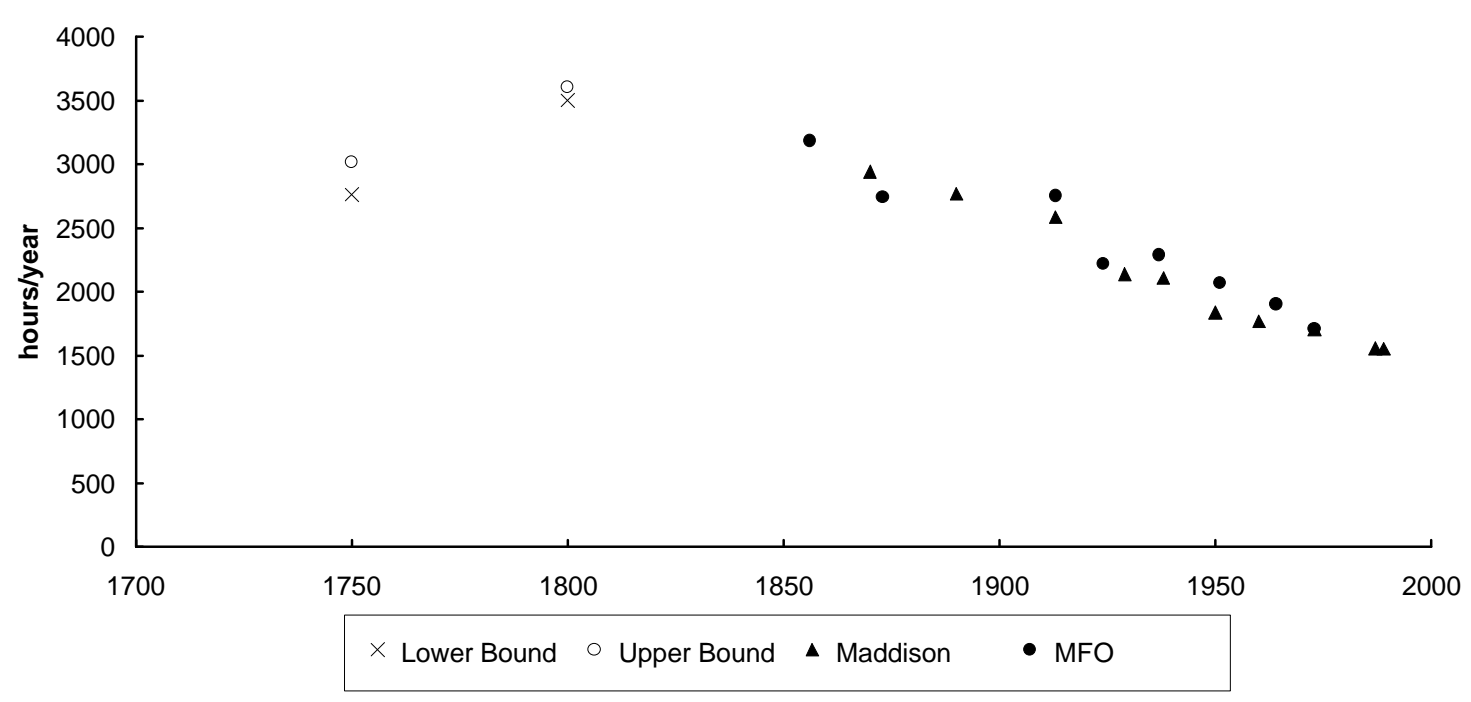

Figure 4

Developments over the long run lend empirical support to suggestions in the literature that changes in labour input described an inverse U. The length of the working year in 1750 was similar to the second half of the nineteenth century. In 1800, both upper and lower bound estimates are higher than any observed since 1850. Around 1750, annual labour input reached levels equivalent to those in the 1850/70s. The speed of change was also high. If our calculations are approximately correct, then the development between 1750 and 1800 was dramatic. The rise in annual labour input per person over fifty years $(+585$ to +738$)$ is roughly as large as the reduction in working hours between 1870 and $1938(-717) .{ }^{45}$ These findings are more or less independent of the data used for the period after 1850 - long-run trends in working hours in the Maddison and the MFO series are broadly similar. While these changes took place in less than fifty years in the eighteenth century, ${ }^{46}$ the decline of working hours by the same order of magnitude required almost seventy years.

\section{FACt OR Fiction? Testing the New Method}

We have established the timing of activities as well as changes in time use between the middle and the end of the eighteenth century using a new and as yet untested method. There are, however, numerous sources of potential bias, and it is important to demonstrate that none of these affects the accuracy of our results. In addition to internal consistency checks, I also perform comparisons with data from other sources.

45 Calculated from the Maddison series. The difference would be even more pronounced if we use the series without adjustments for agriculture.

46 Since data was collected for more than one year, it is probably best to use the middle of both observation periods to determine the length of the interval. In subsequent calculations, an interval of 46 years is assumed. 


\section{Hours and Days - Sample Selection Bias}

The duration-based estimates that we inferred from the start and end of activities ought to match up with the proportions of activities reported in our sample. In the data analysis section, we have inferred the duration of work per day from the time of starting and stopping work. This estimate was refined further by taking mealtimes into account. Let us assume, for the purpose of comparison, that every day in the year showed exactly the same pattern of time-use. To calculate the number of minutes of work in society's 'great day' of 1440 minutes, we also have to correct this daily average for the number of working days in the year. If earning a living required, say, an average of 144 minutes per day, then $10 \%$ of the witnesses in our sample should have reported that they were engaged in work-related activities. To ascertain the direction of change, we do not even have to assume that each sample is free from bias. Even if some sampling bias exists at any given time, we should still be able to capture changes in time use accurately if the nature of the bias does not change between two benchmark years.

For 1760, I estimate that there were 672 minutes of work per (working) day. I also calculated that, for two thirds of the population at least, Monday and a list of holidays plus Sunday were days of rest. As a result, I calculate that on average seven hours and 50 minutes of society's 'great day' in 1760 were devoted to work. After excluding all sleep-related activities (which must be subject to undersampling), 56.1\% of the remaining activities in 1760 are work-related. ${ }^{47}$ With 8 hours of sleep, this suggests an average of eight hours and 58 minutes of work. The difference is not small, but the order of magnitude is similar. More importantly, change over time calculated on the basis of these two independent methods is virtually the same. For 1800, the duration-based method gives an estimate of 583 minutes of work per day, $24 \%$ more than in 1760 . The control estimate suggests 650 minutes, an increase by $20.8 \% .^{48}$

In the calculation of working hours from the percentage of witnesses' activities, assumptions about the length of sleep are particularly important. Instead of assuming, in an ad hoc fashion, 8 hours of sleep per day, we can use the duration-based estimates. This somewhat dilutes the independence of the control estimate since it is now partly based on the duration inferred from the timing of events. Table 6 gives estimates for hours of work, based on calculated hours of sleep (including upper and lower bounds) in 1760 and 1800.

47 Either work itself or the starting or stopping of paid work.

48 Small differences between these figures and the ones presented in figure 2 and 3 are possible since I also included agriculture in the calculations for all of Britain. 
Table 6: Hours of Work - Sensitivity to Assumptions about Sleep

\begin{tabular}{|c|c|c|c|c|c|c|c|c|}
\hline & & & $\begin{array}{c}\text { duratio } \\
n \\
\text { estimat } \\
e\end{array}$ & $\begin{array}{c}\text { control } \\
\text { estimat } \\
e\end{array}$ & $\Delta$ & $\begin{array}{c}\text { index } \\
\text { duratio } \\
n\end{array}$ & $\begin{array}{l}\text { index } \\
\text { control }\end{array}$ & $\Delta$ \\
\hline \multirow{4}{*}{ mean } & sleep $=8$ hours & 1760 & 7.8 & 8.9 & -1.1 & 100.0 & 100.0 & \multirow{3}{*}{3.1} \\
\hline & & 1800 & 9.7 & 10.8 & -1.1 & 124.4 & 121.3 & \\
\hline & $\begin{array}{l}\text { sleep }=7.27 \mathrm{~h} \\
(1760)\end{array}$ & 1760 & 7.8 & 9.4 & -1.6 & 100.0 & 100.0 & \\
\hline & $6.35 h(1800)$ & 1800 & 9.7 & 11.9 & -2.2 & 124.5 & 126.6 & \multirow[t]{2}{*}{-2.1} \\
\hline $\begin{array}{l}\text { upper } \\
\text { bounds }\end{array}$ & sleep $=8.3 h(1760)$ & 1760 & 7.8 & 8.8 & -1.0 & 100.0 & 100.0 & \\
\hline \multirow[t]{2}{*}{$\begin{array}{l}\text { upper } \\
\text { bounds }\end{array}$} & $\begin{array}{l}\quad 7.23 \mathrm{~h}(1800) \\
\text { sleep }=6.35 \mathrm{~h} \\
(1760)\end{array}$ & $\begin{array}{l}1800 \\
1760\end{array}$ & $\begin{array}{l}9.7 \\
7.8\end{array}$ & $\begin{array}{c}11.3 \\
9.9\end{array}$ & $\begin{array}{l}-1.6 \\
-2.1\end{array}$ & $\begin{array}{l}124.4 \\
100.0\end{array}$ & $\begin{array}{l}128.9 \\
100.0\end{array}$ & -4.5 \\
\hline & $5.68 \mathrm{~h}(1800)$ & 1800 & 9.7 & 12.4 & -2.7 & 124.5 & 125.3 & -0.8 \\
\hline
\end{tabular}

Independent of the assumptions about sleep, there appears to be a slight tendency for the duration-based method to underestimate the number of working hours - or for the frequencysample method to overstate them. There is no way to ascertain which method is correct. However, since there is some reason to believe that there is a reporting bias in favour of outdoor activities, it is likely that the frequency method overstates work activities (outside the home) systematically. The direction and speed of the rise in annual labour input is quite independent of the assumptions made about hours of sleep, as table 6 demonstrates. The difference of the percentage change between 1760 and 1800 implied by the two methods is never larger than $5 \%$.

There is an alternative explanation why we find a systematic difference between the estimates of working hours in table 6. Since the beginning and end of meals was not clearly distinguished by witnesses, I resorted to observations on the interval during which these activities were reported. For the final calculation, ninety minutes were deducted from the interval between starting and stopping work in order to account for meals. This cavalier approach can possibly be improved by using the direct evidence on the number of individuals engaged in eating during waking hours. In 1760, 2.4\% of witnesses claimed to have had breakfast. Assuming 8 hours of sleep for simplicity, this implies 23 minutes spent on the first meal of the day. 'Dinner' (i.e. lunch) was reported as the prime activity at the time of the crime by $3.7 \%$ of witnesses, which is equivalent to 35 minutes. For 1800 , the respective figures are 13 and 50 minutes. If we augment our calculation of working hours (based on the time of starting and stopping) with these figures, this suggests 8 hours and 21 minutes in 1760 and 10 hours 7 minutes in $1800 .^{49}$ The difference between the two methods is reduced to a mere 37 minutes in 1760 and 43 minutes in 1800. The frequency-based method now suggests an increase in annual labour input by $20.8 \%$, whereas the duration-based approach gives $21.2 \%$.

The conclusion from these consistency checks can only be that, whether we use the timing of activities given by witnesses or the proportion of the total engaged in certain 49 I have reverted to assuming 8 hours of sleep. The justification is that the two methods should be kept as independent as
possible if one is to serve as a test of the other. 
activities, overall estimates of time-use are robust. While the results from these independent methods do not always agree perfectly with each other, they indicate an almost identical direction and magnitude of change over time. What we cannot test by comparing the results from our two methods is the possibility of sampling bias amongst the witnesses themselves.

\section{The Representativeness of Witnesses and Changes in Sample Composition}

How representative of London's population are our witnesses? Since we cannot test this aspect directly, I shall follow the standard procedure of choosing an additional characteristic which is recorded for witnesses and also known for London's population. ${ }^{50}$ Hard data on London in 1800 are not abundant. Schwarz has nonetheless estimated shares in the male working population according to socio-economic status. He concludes that only 2-3 percent of London's adult male population belonged to the upper income group (over $£ 200$ p.a.). The middling sort contributed another 16-21 percent. The remainder he calls 'the working population'. Schwarz also provides a more detailed (and more tentative) breakdown of this residual. $^{51}$

If we can show that witnesses testifying before the Old Bailey came from a similar background, it would be much more likely that they are a representative sample of the population as a whole. Definitions of socio-economic class are not always clear-cut, and not all of our witnesses provide sufficient information about themselves to allocate them to a particular group. I follow Schwarz's definition that the middling classes consisted of 'anyone below an aristocrat or very rich merchant or banker, but above a journeyman worker or smallscale employer in one of the less prestigious trades.' Small shopkeepers are not included in this group, according to Schwarz; they contribute another 9-10 percent to the male working population. ${ }^{52}$ In the Old Bailey Sessions Papers, I was unable to distinguish between the 'middling sort' and shopkeepers in this way. It therefore seemed more appropriate to combine these two categories for purposes of comparison. In 1800, 793 of the male witnesses gave an occupational description that allows us to allocate them to one of Schwarz's groups. The results are summarised in table 7, where I also give upper and lower bounds from Schwarz: ${ }^{.3}$

50 A good example of this technique can be found in Johnson and Nicholas 1995, p. $10 \mathrm{ff}$.

51 Schwarz 1992, p. 57.

52 Schwarz also analyses the female working population. Since proportions can not be derived from his description, the analysis is not extended to women.

53 I used the upper and lower bound estimates described in Schwarz 1992, p. 57. The semi- and unskilled category was then derived as a residual. 
Table 7: Composition of the Male Labour Force

\begin{tabular}{lrrr}
\hline & \multicolumn{1}{c}{ Schwarz } & Old Bailey - \\
& lower bound & upper bound & 1800 \\
\cline { 2 - 4 } upper income & 2 & 3 & 1.64 \\
middle income+shopkeepers & 25 & 29 & 20.05 \\
self-employed & 5 & 6 & 4.79 \\
artisans & 23.8 & 21.7 & 20.68 \\
semi- and unskilled & $(44.2)$ & $(40.3)$ & 52.84 \\
& & & \\
sum & 100 & 100 & 100 \\
\hline
\end{tabular}

The distributions are remarkably similar. For the upper income group as well as for the selfemployed and artisans, the figures are almost identical. Yet the estimate from the Old Bailey Sessions Papers for the combined 'middle income and shopkeeper' group is below even the lower bound given by Schwarz, and there seem to be too many witnesses in the 'semi- and unskilled' group. How do we assess the importance of the similarities and differences? Chisquared tests fail to reject the null hypothesis of no significant difference. Another technique commonly used to explore the relationship between observed sample characteristics and the control group is simple correlation analysis. ${ }^{54}$ The correlation between the population shares from Schwarz and the witnesses in the Old Bailey Sessions Papers is always 0.9 or above - a high degree of similarity. We can therefore conclude that, if we use social class as our standard of comparison, no significant difference between our sample and the population can be found. However, this should not be confused with positive proof that witnesses are representative of the (male working) population at large.

Ideally, we would want to apply the same tests to the sample from the 1750 s and early 1760s. Unfortunately, there are no sufficiently detailed and reliable estimates of labour force composition for the earlier period. Instead, we can examine the proposition that shifts in sample composition between the two benchmark years bias our results. The most striking finding in our empirical section was the increase in the number of working days per year. It could be argued that the more intensive working year is not due to any changes in actual working practices in each socio-economic group. Rather, it could reflect changes in the number of witnesses coming from individual groups. If, say, the semi- and unskilled worked appreciably longer than the rest of the population, and their share in the total number of witnesses rose between 1750 and 1800, then one of our main findings might have been caused by a statistical illusion. ${ }^{55}$ Such a shift in selection bias might even be expected as watch ownership spread from the top of the social hierarchy to the lower ranks. Table 8 compares sample composition in 1760 and 1800.

54 Johnson and Nicholas 1995, p. 10.

55 Strictly speaking this would only be true if the witnesses are not a representative sample of the population. If they are, then the rise in labour input would be to due shifts in labour force composition. Society's 'great day' would still have changed, but for very different reasons. 
Table 8: Sample composition in 1760 and 1800

\begin{tabular}{lrr}
\hline & Old Bailey-1760 Old Bailey-1800 \\
\cline { 2 - 3 } upper income & 1.4 & 1.6 \\
middle & 27.6 & 20.1 \\
income+shopkeepers & & \\
self-employed & 2.8 & 4.8 \\
artisans & 14.3 & 20.7 \\
semi- and unskilled & 54.0 & 52.8 \\
& & \\
sum & 100 & 100 \\
\hline
\end{tabular}

The share of the semi- and unskilled remained virtually unchanged between the middle and the end of the eighteenth century, slipping by a little more than one percent. This is eloquent testimony against the idea that a 'trickling down' of watch ownership biased our results.

The main change in table 8 is that the number of artisans (not self-employed) rises from 14 to 20 percent, while those in the middle income range plus shopkeepers slip from 27 to 20 percent. Is the magnitude of these differences sufficient to explain a rise of aggregate labour input by at least 20 percent? Let us assume that employed artisans worked longer than the population at large, and that the increase in working days can be attributed to their increased share. How much longer than the average witness would they have to work to influence the aggregate to this extent? The average length of the working year (D) is equivalent to

$D=\sum_{i=1}^{m} p_{n} d_{n}$

where $\mathrm{p}_{\mathrm{n}}$ is the share of the $\mathrm{nth}$ group in the total (working) population, $\mathrm{m}$ is the number of different occupational groups, and $\mathrm{d}_{\mathrm{n}}$ is the length of the working year for the nth group. $\mathrm{D}^{1800}$ was (at least) 20 percent longer than $\mathrm{D}^{1760}$. Using the labour input of the remaining population as a numeraire as well as the shifts in sample composition from table 8 , we can now calculate relative efficiencies that would explain the observed rise in labour input. ${ }^{56} \mathrm{We}$ have to solve

$$
\begin{aligned}
& \frac{\left(p_{r}^{1800}\right)+\left(p_{a}^{1800} d_{a}\right)}{\left(p_{r}^{1760}\right)+\left(p_{a}^{1760} d_{a}\right)} \geq 1.2 \\
& \Leftrightarrow d_{a} \geq \frac{1.2 p_{r}^{1760}-p_{r}^{1800}}{p_{a}^{1800}-1.2 p_{a}^{1760}}
\end{aligned}
$$

[ $\mathrm{p}_{\mathrm{r}}$ is the share of non-artisans in the population, $\mathrm{p}_{\mathrm{a}}$ is the artisans' share, and $\mathrm{d}_{\mathrm{a}}$ is the relative length of the artisans' working year, compared to the rest]

56 There is no particular reason why $\mathrm{d}_{\mathrm{a}}$, the relative length of the working year of artisans compared to the rest of the population, should be constant over time. If we allow it to vary, there will be no unique solution to our problem. 
If the increase in the artisans' share boosted annual labour input by twenty percent, then they would have had to work at least 6.7 times longer than the average of the remaining population. This is unlikely. It appears safe to conclude that shifts in sample composition were not decisive for the changes observed in the data analysis sections.

The same logic can be applied to sectoral shifts among our witnesses. Trade and services, for example, were famous for long working hours, and it is theoretically possible that an increase in their share of all respondents boosted the probability of finding people at work. ${ }^{57}$ The number of witnesses engaged in trading activities rose from 122 in 1749/63 to 168 in $1799 / 1803$; in services, there was a fall from 248 to $218 .^{58}$ The aggregate increase in both categories is therefore equivalent to 4.3 percent. How much harder would those employed in services and trade have had to work to effect a 20 percent rise in total labour input, given the small aggregate increase in their number? As is obvious from eq. 12.2, there is no non-negative value for $\mathrm{d}_{\mathrm{a}}$ that allows an increase of 20 percent, given that $\mathrm{p}_{\mathrm{a}}^{1760}=0.37$ and $\mathrm{p}_{\mathrm{a}}^{1800}=0.386$. Since the increase in size of the possibly more work-intensive trades is very small, even for very high values of $d_{a}$, the ratio of labour input in 1800 to 1760 converges towards 1.043 . Non-negative solutions to eq. 4 require that

$p_{a}^{1800 / p_{a}}{ }^{1760} \geq 1+(\mathrm{i} / 100)$

where $\mathrm{i}$ is the percentage increase in labour input. Because eq. 5 is not fulfilled, there is no non-negative solution for $\mathrm{d}_{\mathrm{a}}$. Changes in the sectoral composition of our sample were not responsible for the increase in labour input.

\section{The Uneven Distribution of Crimes}

Crimes were not committed with equal frequency throughout the day. Hence, the number of observations provided by witnesses differs from hour to hour, and it is theoretically possible that this imparts a bias to our calculations. For example, there may be as many people starting work at, say, 6 in the morning when crime is rare, as at 8, when it is becoming more common.

We can explore the consequences of such a possible bias in more detail by adopting a simple reweighting scheme. For each one-hour interval, we know the number of statements by all witnesses. In 1800, for example, there was an average of 40.9 observations during any onehour period..$^{59}$ For the interval from 16:00 to 17:00, however, we have 50 statements; consequently, we would reweight any time-use information by a factor of 0.82 .

\footnotetext{
57 Cf. the long working hours for those in trading and the service sector given by Campbell (1747).

58 Allocating individuals to either category is partly arbitrary.

59 There were 19 exact descriptions of an individual's activity for which the day but not the time were recorded.
} 
Table 9: Reweighted and Original Time of 4 Main Activities, 1760 and 1800

\begin{tabular}{lcccc}
\hline & $\begin{array}{c}\text { Rising in the } \\
\text { Morning }\end{array}$ & Going to Bed & $\begin{array}{c}\text { Starting } \\
\text { Work }\end{array}$ & Stopping Work \\
\cline { 2 - 5 } 1760 & & & & \\
original & $6: 10$ & $22: 50$ & $6: 50$ & $18: 50$ \\
reweighted & $6: 17$ & $23: 27$ & $7: 38$ & $18: 35$ \\
& & & & \\
1800 & $5: 53$ & $23: 21$ & $6: 33$ & $19: 06$ \\
original & $5: 34$ & $23: 58$ & $6: 10$ & $18: 52$ \\
reweighted & & & & \\
\hline
\end{tabular}

Note: * indicates a difference that is significant at the 95 percent level.

In the majority of cases, the difference between the reweighted and the original estimates is minute. Witnesses rose at 6:10 in 1760 if we use the 'naive' method, and at 6:17 when we correct for the fluctuating incidence of crime. In the few cases where the difference is larger, the standard error bands of the original and the reweighted estimate overlap. We can therefore conclude that the main structure of daily life is not biased by the timing of crime.

\section{Memory Decay and Recall Period}

How long was the interval between the crime and the court trial? Both dates are given in the Old Bailey Sessions Papers, so we can easily reconstruct the time period over which witnesses had to recall their activities. The number of sessions at the Old Bailey varied from year to year, but six to eight were common between the middle and the end of the eighteenth century. Since approximately 50 days had passed since the last session, we would expect that the average witness's memory had to bridge 25 days. In addition to this minimum period, legal procedures (establishing evidence etc.) or a backlog of cases before the court could lengthen the period between crime and trial.

The average lag 1749-63 was 45.6 days (median 30); in 1799-1803, it had been reduced to 39.2 days (median 25) ${ }^{60}$ Compared with modern sociological studies, where recall periods of a few days normally prevail, these are long intervals. Are recall period and data quality in any way related? There is one immediate indication of faulty reporting in the verbatim reports - if the day of the week mentioned by the witness and the date (which implies a certain weekday) do not agree. ${ }^{61}$ This was true in a number of cases, as the empirical sections demonstrated. If we can now show that the lag between crime and hearing has no appreciable influence on the quality of recollections in this regard, then there is even less reason for concern about the length of the recall period. To test this possibility, I assigned the value 0 whenever there was agreement between the two days, and 1 otherwise. We would now expect

60 The lag length for the two samples is not identical, but there is no significant difference - the confidence intervals overlap. This provides further indirect evidence that the two samples were not generated by vastly different judicial procedures.

61 Implicit in this method is that witnesses (and not scribes at the court etc.) are responsible for errors. This approach would be invalidated if the errors of witnesses varied inversely with the scribes' errors, depending on lag length. Such a possibility is, however, purely speculative. 
the probability of this new variable being equal to 1 to vary with the lag between trial and crime if witnesses' reports in general become less accurate over time. The result from a logistic regression is as follows: 
1749-63:

$\mathrm{C}=-1.42+0.0044 \mathrm{LAG}$

(42.1) (1.6)

Model $\chi^{2}=1.54$

1799-1803:

$\mathrm{C}=-2.97-0.0039 \mathrm{LAG}$

(112.7) (0.4)

Model $\chi^{2}=0.569$ 
$[\mathrm{C}=$ control variable, 0 if the recorded and inferred day agree, 1 otherwise. $\mathrm{LAG}=$ number of days between the crime and the trial; Wald-statistic in parentheses)

The $\chi^{2}$-statistics show that the models don't explain variation in the data adequately, and the Wald statistic on the delay between crime and court session is insignificant. Even if the estimated coefficient for 1749-63 were significantly different from 0 , the effect would be very small. For the period 1799-1803, the coefficient on LAG is even wrongly signed, which implies that, the longer the recall period, the less likely mistakes were. ${ }^{62}$

Hence, there is no evidence that links the recall period to data quality. Witnesses were sometimes unable to give all the details we would want to know for a variety of reasons, but forgetfulness because of an extended recall period was probably not one of them.

\section{Work on a Cheshire Canal}

So far, I have largely examined issues of internal consistency - I have tested the possibility of witnesses' accounts contradicting themselves, at least on the issue of time-use, of unobserved shifts influencing our results, and of inconsistencies arising from potential sampling biases. The results have been encouraging. Yet what is really at issue is how representative the judicial evidence from a London court is. Are shifts in time-use found among those testifying before the Old Bailey indicative of patterns elsewhere? I use new data from an additional source to examine this question.

The evidence comes from the day wage book (repairs) from the Burnton and Western Canal in Cheshire in $1801 .^{63}$ Payments to carpenters, sawyers and yard labourers are documented. Their work was classified as 'extra labour'. This implies that they were not regarded as a regular part of the company's labour force. During the year 1801, however, the individuals named in the wage book do not change very much. What fluctuates in the course of the year is the number of them that the company employed. Consequently, there was a more or less stable group of men available for work on the canal. The company employed their services as it saw fit, but it rarely turned to outsiders. The workers whose wages are documented may have been a reserve army of labour, but its composition was very stable.

The wage book is not an ideal source for our purposes. Peculiarities of labour demand on the canal may have made employment patterns highly untypical. However, the possibility that work on the canal was timed in an usual way should only concern us if the wage book data and witnesses' accounts contradict each other. If they do not, it appears highly unlikely that both the Old Bailey Sessions Papers and the canal wage book recorded the same aberrant work patterns - the former pertains to 1000 individuals in virtually all professions. A second possible objection is that the fluctuating type of employment may have induced workers to seek work elsewhere, leaving us with an understatement of annual working days. Since we find a strong upward movement of labour input and a very long working year in absolute terms, this would only be a problem if the number of hours worked on the canal is much lower than implied by the Old Bailey witnesses. Finally, there is no information on the number of hours

\footnotetext{
62 The exercise based on the precision of time-use information could not be repeated because only a sample of 40 observations was collected for 1799/1803.

63 P.R.O. (Kew) Rail 883-189.
} 
worked per day. Occasionally, labourers receive more than a day's wage, which implies that they worked longer than normal, but there is no indication either of these regular hours nor the exact amount of overtime. For our purposes, the absence of information on hours of work is not as unfortunate as may be supposed - the our main finding concerns weekly and annual patterns of labour and leisure.

During 1801, a total of 5,924 man-days were worked on the canal. The maximum number of workers employed on any one day was 42 ; the smallest observed value is zero. On average, 16 men are employed for repair work and the like. Work on the Burnton and Western Canal in 1801 was strongly seasonal. Because the degree of seasonality is broadly comparable in both samples, we can argue that the pattern of work captured is similar. ${ }^{64}$

We are also interested in the days when work stopped, and if the weekly and annual patterns in Cheshire is similar to the London one. There are only 25 days on which nobody worked. All of them are Sundays; no other day saw everyone refraining from working. During the rest of the week, the number of men at work is fairly constant. Table 10 compares the data from the Old Bailey with the weekly pattern of work on the canal. ${ }^{65}$

Table 10: Work on the Canal - Days

\begin{tabular}{|c|c|c|c|}
\hline$\frac{\text { Old Bailey-1800 }}{\text { Count }}$ & $\begin{array}{c}\text { \% of overall } \\
\text { total } \\
(=\text { sum of col. } \\
\text { 1) } \\
\text { (2) }\end{array}$ & $\frac{\text { Canal }}{\text { Count }}$ & $\begin{array}{c}\% \text { of total } \\
\text { (4) }\end{array}$ \\
\hline 35 & 6.2 & 199 & 3.4 \\
\hline 79 & 13.4 & 974 & 16.4 \\
\hline 85 & 14.7 & 976 & 16.5 \\
\hline 99 & 17.1 & 945 & 16.0 \\
\hline 85 & 14.7 & 910 & 15.4 \\
\hline 90 & 15.5 & 958 & 16.2 \\
\hline 106 & 18.4 & 962 & 16.2 \\
\hline
\end{tabular}

In 1800, there are slightly more observations on Sunday, but the difference is small. On the canal, the days of the working week register almost identical manning levels. The variation is somewhat higher in the witnesses' accounts - as is only to be expected since there is more than one profession in the sample. In both datasets, Sunday appears to be a day of rest, and Monday shows no significant divergence from other working days. The (Pearson) correlation coefficient between the two relative frequencies (columns (2) and (4)) is 0.91, and the Spearman rank correlation coefficient has a value of 0.93 . As regards the weekly cycle of work and rest, the evidence from the Burnton and Western Canal in 1801 does not contradict the data from the Old Bailey in 1799/1803.

64 Agreement between the two series is not always perfect; the trough during the summer months, for example, seems to be more acute in the Old Bailey data than on the canal. Overall, similarity between the two datasets is not small. While the more sensitive Pearson correlation coefficient only suggests a value of 0.35 , the Spearman rank correlation coefficient is 0.96 - far higher than values that are generally regarded as acceptable in the literature (cf. Johnson and Nicholas 1995, p. 10ff).

65 Note that the Old Bailey data from 1800 in table 10 refers to most narrow definition of work; levels for broader definitions of work are higher, but the weekly pattern is broadly similar. 
We have thus demonstrated that one source of growing labour input that we inferred from the Old Bailey, the decline of St Monday, was also present on the canal. Is this also true for the second cause of the lengthening working year, the disappearance of holy days? In deciding whether a day was normally used for work or not, it will be convenient to define a certain number of men in employment that clearly marks a working day. However, the same number of men at work may have been high during the summer and very low in the autumn. I will consequently focus on the relative difference between the number of men at work on a specific day and the seven-day moving average. If we decide that fifty percent of the moving average is a reasonable cut-off point, then 44 days were used for rest. All but three of these are Sundays. The result is not very sensitive to the cut-off point we use. At 30 percent, it is 41; at 70 percent, it is 48 . This implies that not even every Sunday was a day off. The consequence of moving to a higher threshold is simply to add additional Sundays; there are still only three other non-Sundays.

Clearly, none of the traditional holidays persisted, at least on the canal in Cheshire. While the Old Bailey Sessions Papers allow us to observe a large number of individuals, but each only over a very short period, the nature of the data in the wage book is exactly the reverse: the number of individuals is comparatively small (about 1/60 of the number in the Old Bailey reports), but we are able to track each one over the course of an entire year. Also, the two datasets come from different geographical areas. This lends some support to our procedure of treating London developments as representative of England as a whole. Both methods agree on the main points - St Monday and old holy days held no importance any more in 1800, and the weekly and annual cycles of work and rest are remarkably similar. Unfortunately, we cannot repeat the experiment with data from the same source for 1760 . Our evidence would be fully corroborated if there were evidence from another independent source of traditional practices still persisting in 1760 . 


\section{IMPLICATIONS}

For our period, evidence on real wages on the one hand and on patterns of consumption on the other present a conundrum. Schwarz finds a rapid fall in London real wages between the middle and the end of the eighteenth century. ${ }^{66}$ Lindert and Williamson also find a reduction in real wages, but of a much smaller magnitude. ${ }^{67}$ At the same time, calculations of consumption per head of population show a small gain between 1760 and 1801. Crafts, using his new output figures, suggests that consumption rose by almost exactly ten percent between 1760 and $1800 .{ }^{68}$ Also, as has been noted elsewhere, probate inventories record a rising stock of consumer goods being passed on from one generation to the next. ${ }^{69}$ Can the new estimates for labour input help to resolve the puzzle?

Consumption per capita net of saving will equal total wages earned by the labour force, divided by the size of the population. ${ }^{70}$ As a first approximation, changes in income per head of population should then be the sum of changes in hours worked per member of the labour force, the labour force participation ratio, and the real wage. We can now combine the new estimates for labour input with some of the real wage indices in the literature to examine if there is still evidence of conflicting trends. Table 11 gives the results. I have calculated the implied change in consumption per capita between 1760 and 1800, using both the Schwarz and the Lindert and Williamson series. ${ }^{71}$

66 Schwarz 1985, p. 28 f.

67 Lindert and Williamson 1983, table 5, p. 13.

68 Crafts 1985, table 5.2, p. 95.

69 King 1996. For general trends, cf. DeVries 1993.

70 This only applies, of course, if we disregard consumption financed by profits or income from private wealth. Since I am inferring rates of change over time, my results will only be biased if income from these sources did not fluctuate in parallel with the wage bill.

71 I used their real wage for 'all blue collar workers', Lindert and Williamson 1983, table 5, p. 13. The improved series in Feinstein (1994) was not used since it only starts in 1780. 
Table 11: Observed and Implied Change of Consumption, 1760-1800

\begin{tabular}{|c|c|c|c|c|c|c|}
\hline & \multicolumn{3}{|c|}{ upper bounds for labour input } & \multicolumn{3}{|c|}{ lower bounds for labour input } \\
\hline & 1760 & 1800 & \% change & 1760 & 1800 & \% change \\
\hline \multicolumn{7}{|l|}{ Schwarz wage series } \\
\hline labour input (hours/year) & 2763.00 & 3501.00 & $+27 \%$ & 3020.00 & 3605.00 & $+19 \%$ \\
\hline labour force participation ratio* & 46.50 & 44.86 & $-4 \%$ & 46.50 & 44.86 & $-4 \%$ \\
\hline wages, London** & 117.50 & 82.30 & $-30 \%$ & 117.50 & 82.30 & $-30 \%$ \\
\hline C p.c. implied $(1760=100)$ & 100.00 & 85.62 & $-16 \%$ & 100.00 & 80.66 & $-19 \%$ \\
\hline C p.c. $(1760=100)$ & 100.00 & 110.14 & $+10 \%$ & 100.00 & 110.14 & $+10 \%$ \\
\hline C implied as a \% of C p.c. & & & 77.74 & & & 73.24 \\
\hline \multicolumn{7}{|c|}{ Lindert and Williamson wage series } \\
\hline labour input (hours/year) & 2763.00 & 3501.00 & $+27 \%$ & 3020.00 & 3605.00 & $+19 \%$ \\
\hline labour force participation ratio* & 46.50 & 44.86 & $-4 \%$ & 46.50 & 44.86 & $-4 \%$ \\
\hline wages, all blue collar workers** & 56.29 & 51.73 & $-8 \%$ & 56.29 & 51.73 & $-8 \%$ \\
\hline C p.c. implied $(1760=100)$ & 100.00 & 112.34 & $+12 \%$ & 100.00 & 105.49 & $+5 \%$ \\
\hline C p.c. $(1760=100)$ & 100.00 & 110.14 & $+10 \%$ & 100.00 & 110.14 & $+10 \%$ \\
\hline C implied as a \% of C p.c. & & & 102.00 & & & 95.78 \\
\hline
\end{tabular}

C implied as a \% of C p.c. For the period 1801-1879, the labour force participation ratio rose by 0.8 percent for every 1 percent increase in the share of the population of working age (tstatistic 5.4, $\mathrm{R}^{2}=0.8$ ). On the basis of this relationship, the Wrigley and Schofield figures on population structure were used to extrapolate backwards. 
If the Schwarz series is used, the rise in annual labour input is insufficient in either case to compensate for the fall in real wages and the declining labour force participation ratio. ${ }^{72}$ However, without the rise in labour input, we would have expected consumption p.c. to fall by 32 percent because of falling wages and the rising dependency burden. Because of the increase in working hours, the implicit change in consumption p.c. is only $-16 \%$ - a sizeable reduction of the puzzle. The Lindert and Williamson series, combined with my upper bound estimate of changes in labour input, gives allows us to resolve the puzzle almost completely - it implies a rise in consumption p.c. by $12 \%$ vs. the $10 \%$ calculated by Crafts. In this case, even the lower bound estimate for time-use tips the scales in favour of growing standards of consumption the calculated change per capita is $5 \%$. These results demonstrate that the implied trend in consumption is most sensitive to the real wage index used. More working hours go some way towards resolving the paradox noted above; yet for the final result to be positive, we have to believe that the Lindert and Williamson series is superior to Schwarz's. This cannot be tested directly by the evidence assembled in this paper.

The time-use data has further implications for the history of income. Lindert and Williamson recently re-examined Massie's social tables for England in 1759. In addition to revising his estimates for occupational composition, they argue that his guesses of family income at this time are too low. ${ }^{73}$ Estimates of mean weekly income appear unconvincing when compared with daily wage rates from other sources. Dividing the former by the latter implies a working week of only 4.79 days. ${ }^{74}$ Lindert and Williamson deem this figure much too low since they believe that there is overwhelming evidence for a six-day working week at this time (or more than $25 \%$ more than the implied figure), citing Bienefeld as a source. First, it is important to note that Bienefeld was anything but firm on the matter, merely stating that the six-day week was generally regarded as the norm. ${ }^{75}$ Second, they do not take account of the large number of public and religious festivals still prevailing at this date. Converting scenarios A and B above suggests 4.83 and 5.27 working days per week. Scenario A therefore only diverges from Massie's figure by 0.8 percent, scenario B by 10 percent. Our finding of a comparatively short working week in 1760 resolves the inconsistency in favour of Massie and it vindicates the accuracy of the contemporary wage assessments used by Lindert and Williamson.

The value of these calculations is twofold. While it must be stressed that our simplifying assumptions diminish the accuracy of the exercise, and the time-use data almost exclusively refers to London, it is nonetheless reassuring that our revised estimates for labour input help to resolve some of the puzzles posed by conflicting evidence on consumption, income and real wages. This is important if we believe that economic history should strive for a coherent image of the past. By fitting another piece into the puzzle (and connecting two disparate parts), the existing results and our findings reinforce each other. Further, the

72 This need not imply that it is less accurate than the Lindert and Williamson series - trends in London may very well have diverged from national ones.

73 Lindert and Williamson 1982, p. 395 f.

74 Their results are 4.9, 4.6, 4.1 and 4.95, giving an average of 4.64. Since one of their sources for daily wage rates (building labourers) actually gives a range of 20-24 d., I calculated an additional observation from the lower bound (equivalent to 5.4 days). Lindert and Williamson simply used the upper bound, thus biasing the result in favour of their argument.

75 Bienefeld 1972, p. 36ff. 
calculations in table 11 are also of interest for the historiography of the Industrial Revolution, in that they lend further credence to a cautiously optimistic interpretation of its early years.

\section{Total Factor Productivity}

At present, the historiography of the Industrial Revolution seems to diminish the importance of productivity growth by the decade. For 1760-1801, research during the past 15 years has halved its importance. For the three decades to 1831, there was a decline from $1.3 \%$ p.a. to $0.35 \%$ p.a. - a fall equivalent to $73 \%$ (cf. table 12 ). ${ }^{76}$ Recent advances in the measurement of capital formation and output growth have greatly increased the accuracy of TFP estimates. ${ }^{77}$ The level of sophistication is such that only 'declining marginal returns' can be expected from further contributions concerned with output growth and the rate of investment. The same is not necessarily true in the case of labour input, where estimates are normally based on the Wrigley/Schofield data for population growth. ${ }^{78}$

Table 12: Estimates of TFP Growth

\begin{tabular}{|c|c|c|c|c|}
\hline & $\Delta Y / Y$ & $\Delta K / K$ & $\Delta L / L$ & $T F P$ \\
\hline \multicolumn{5}{|l|}{ Crafts } \\
\hline $1760-1801$ & 1 & 1 & 0.8 & 0.1 \\
\hline $1801-1831$ & 2 & 1.5 & 1.4 & 0.55 \\
\hline \multicolumn{5}{|l|}{ Feinstein } \\
\hline $1760-1801$ & 1.1 & 1 & 0.8 & 0.2 \\
\hline $1801-1831$ & 2.7 & 1.4 & 1.4 & 1.3 \\
\hline \multicolumn{5}{|c|}{ Crafts/Harley } \\
\hline $1760-1801$ & 1 & 1 & 0.8 & 0.1 \\
\hline $1801-1831$ & 1.9 & 1.7 & 1.4 & 0.35 \\
\hline
\end{tabular}

Recent work confirms that there was no sudden burst of capital accumulation during a brief period of ten to twenty years, no 'take off' in the sense suggested by Rostow and Lewis. Saving, and consequently, investment, made the largest single contribution to output growth during both periods according to Crafts and Harley. Yet the expansion of capital stock was even slower than initially estimated by Feinstein, and it compares unfavourably with growth rates of other industrialising nations at a similar stage of development. ${ }^{79}$

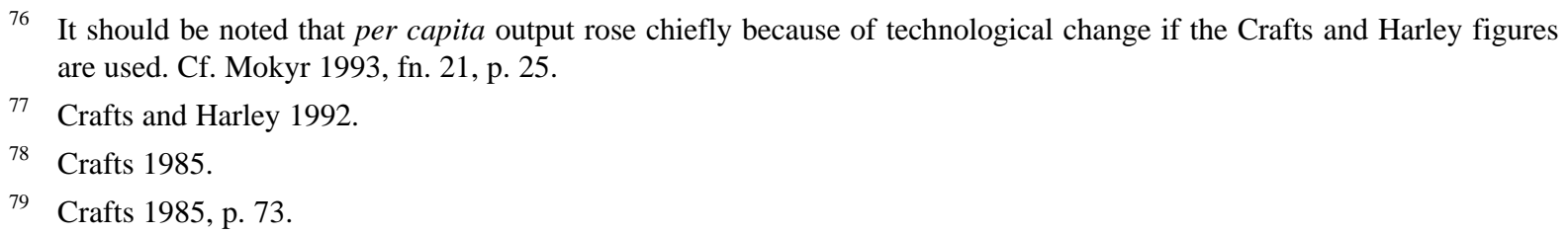


On the basis of our new estimates, we can now argue that $\Delta \mathrm{L} / \mathrm{L}$ grew at a rate of 1.2 to $1.3 \%$ p.a. ${ }^{80}$ This alone would reduce most estimates of TFP growth to negative values, implying that the economy experienced diseconomies of scale. ${ }^{81}$ Yet there is some evidence in modern economic studies that longer working hours have an effect above and beyond additional labour input. A longer working year also increases the availability of capital - tools etc. will go unused for shorter periods. Feldstein uses cross-sectional data on 24 British industries during the postwar period, and finds that the return to working hours was much larger than the return to the number of workers. Craine, using time-series evidence, estimates elasticities of output with respect to working hours in the range of 1.9 to 2.2. One of the most comprehensive studies by Leslie using panel data also found returns greater than $1 .^{82}$ This suggests that the standard TFP formula has to be modified to take differences in the return to labour into account:

$\mathrm{TFP}=(\Delta \mathrm{Y} / \mathrm{Y})-\eta_{\mathrm{K}}(\Delta \mathrm{K} / \mathrm{K})-\eta_{\mathrm{L}}(\Delta \mathrm{L} / \mathrm{L})-\eta_{\mathrm{H}}(\Delta \mathrm{H} / \mathrm{H})$

We can test the sensitivity of our result by using a number of alternative values for $\eta_{H}$ to calculate TFP:

Table 13: Growth Estimates for England, 1760-1801

\begin{tabular}{|c|c|c|c|c|c|}
\hline & & (1) & (2) & (3) & (4) \\
\hline & $\eta_{\mathrm{H}=}$ & 0.5 & 1 & 1.5 & 2 \\
\hline$\Delta Y / Y$ & & 1 & 1 & 1 & 1 \\
\hline$\Delta K / K$ & & 1 & 1 & 1 & 1 \\
\hline$\Delta L / L$ & & 0.8 & 0.8 & 0.8 & 0.8 \\
\hline$\Delta$ working hours (lower bound) & & 0.4 & 0.4 & 0.4 & 0.4 \\
\hline TFP & & -0.1 & -0.3 & -0.5 & -0.7 \\
\hline $\begin{array}{l}\text { \% of output growth explained } \\
\text { by working hours alone }\end{array}$ & & 20 & 40 & 60 & 80 \\
\hline & $\eta_{\mathrm{H}=}$ & 0.5 & 1 & 1.5 & 2 \\
\hline$\Delta Y / Y$ & & 1 & 1 & 1 & 1 \\
\hline$\Delta K / K$ & & 1 & 1 & 1 & 1 \\
\hline$\Delta L / L$ & & 0.8 & 0.8 & 0.8 & 0.8 \\
\hline$\Delta$ working hours (upper bound) & & 0.5 & 0.5 & 0.5 & 0.5 \\
\hline
\end{tabular}

80 Approximately two thirds of this is caused by a larger population, with the remaining third coming from longer working hours.

81 The population grew very rapidly. The idea of a (mild) Malthusian crisis during the late eighteenth century in England was first formulated by Crafts 1985 , p. 77 . It has recently been extended in a more assertive yet less convincing manner: Komlos 1989, chap. 5 and Komlos 1993, passim.

82 Feldstein 1967, tables I,II,IV, V, VI and equations (5)-(8), p. 379-84; Craine 1973, p. 43; Leslie 1983, p. 489f. Solow and Temin $(1978$, p. 12) assume that sixty hours per week is a biologically determined upper limit beyond which output will rise no further; Matthews, Feinstein and Oddling-Smee (1982) argue that the reduction in weekly hours from 65 to 56 between 1856 and 1873 was fully compensated by rising efficiency of the labour force due to shorter hours. There are a number of reasons why the argument about offsetting efficiency gains is of little relevance to our period. First, the starting level in 1760 was not very high - 44 to 51 hours a week in the basic scenario, and 53 to 58 hours if we make the adjustment for agriculture. It is not clear if negative returns can already be expected in this range. 


\begin{tabular}{lcccc}
\hline TFP & -0.15 & -0.4 & -0.65 & -0.9 \\
\hline $\begin{array}{l}\text { \% of output growth explained } \\
\text { by working hours alone }\end{array}$ & 25 & 50 & 75 & 100 \\
\hline
\end{tabular}

For all factor inputs and output growth, I use the figures from Crafts and Harley. ${ }^{83}$ I also use their assumption that capital and labour both have weights of $0.5 .^{84}$ The top half of the table 13 uses the lower bound on the change in annual working hours (from scenario B), equivalent to $0.4 \%$ p.a. The lower half assumes an annual rate of growth equivalent to $0.5 \%$ p.a. Modern empirical studies often give elasticities $\left(\eta_{\mathrm{H}}\right)$ between 1.5 and 2 . If we assume such values, between 60 and $100 \%$ of output growth can be explained, and TFP would have fallen quickly. If the return to increases in working hours is unity, and capital and labour inputs grew at the rates suggested by Crafts and Harley, TFP growth would definitely have been strongly negative (col. 2). A longer working year alone would be sufficient to account for 40 to $50 \%$ of output growth, 1760-1801. The efficiency with which the economy combined factors of production would have fallen at a rate of $0.3 \%$ to $0.4 \%$ p.a. Interestingly, even if we only assume that the return to working hours is equivalent to the one for men (col. 1), then 20 to $25 \%$ of total output growth could still be attributed to the lengthening working year alone. Independent of our assumptions about the return to working hours, total factor productivity was probably falling between 1760 and $1800 .^{85}$

Note, however, that technology may nonetheless have played an important role. Even if the efficiency with which the economy combined factors of production was falling, we assume in our slightly extended Solow framework that there are positive returns to capital, labour, and working hours. That these still existed at a time of spectacular population growth cannot be taken for granted, as Malthus reminds us. It is likely that, in the absence of technological advances, declining marginal returns would have rapidly acted to depress the living standard of the population.

\section{ConClusion}

The purpose of this paper is twofold. It demonstrates the feasibility of a new method for reconstructing time-use in the past, and it has put forward some tentative conclusions for the history of the Industrial Revolution.

At present, the results that have emerged from the Old Bailey Sessions Papers cannot be said to provide wholly accurate measurements of working hours. The merit of the new method is that, while still being far from precise, the estimates based on court records present an improvement because they are based not on anecdotal evidence, but on the everyday patterns of labour and leisure of more than 2,000 individuals. It is hoped that the method presented here can be readily applied to court records from other areas and other periods, ultimately enabling historians to measure historical time-budgets adequately.

83 Crafts and Harley 1992.

84 Crafts and Harley 1992, p. 718.

85 Note that, striktly speaking, the TFP framework assumes constant returns to scale. Cf. Nicholas 1985, p. 576f. The reduction in TFP growth would have been even more pronounced if the output elasticities reported in V.3 had been used, instead of constraining $\eta_{\mathrm{H}}$ to unity. 
The findings presented in this paper partly serve to reinforce the new orthodoxy about the Industrial Revolution. Following the work of Crafts and Harley, the period after the middle of the eighteenth century is now largely seen as one of sluggish increases in productivity, output and the investment ratio. At the same time, structural change was dramatic. ${ }^{86}$ If the argument made in this paper about the wider significance of changes in labour input is correct, a rapid rise in working hours will have to be added to the other areas in which structural discontinuities were conspicuous, such as the re-allocation of the labour force and the unevenness of productivity advance

At the same time, the implications are sufficiently large to substantially revise our view of economic development in England, 1750-1800. Productivity growth - 'ingenuity', in McCloskey's phrase - may have played an even smaller role than is presently assumed in accounts of the British Industrial Revolution. ${ }^{87}$ Output growth would have largely been driven by additional labour input, and the 'Industrious Revolution' (DeVries) was responsible for overcoming the adverse effects of rapid population growth. Abstention seems to have been more important than invention, but it was abstention from leisure - and only partly from consumption - that was at the core of economic growth. ${ }^{88}$

86 Crafts 1985, p. 80-88, p. 115-7. Crafts and Harley 1992, p. 720. For a dissenting view, cf. Berg and Hudson 1992, p. 44.

87 McCloskey 1994, p. $267 f$.

88 DeVries 1994, p. 249ff. 


\section{Bibliography}

\section{Primary sources}

Campbell, R., The London Tradesman (London 1747).

Millan, J., Coins, Weights and Measure of all Nations reduced into English (London 1749).

P.R.O. (Kew) Rail 883-189.

The Whole Proceedings of the Sessions of the Peace, and Oyer and Terminer for the City of London and County of Middlesex. (London, various years).

\section{Secondary sources}

Berg, M. and P. Hudson, 'Rehabilitating the Industrial Revolution', Economic History Review 45 (1992).

Bienefeld, M.A., Working Hours in British Industry: An Economic History (London 1972).

Briggs, A., 'Work and Leisure in Industrial Society', Past and Present 30 (1965).

Crafts, N.F.R., British Economic Growth during the Industrial Revolution (Oxford 1985).

Crafts, N.F.R. and C. Harley, 'Output Growth and the Industrial Revolution', Economic History Review 45 (1992).

Craine, R., 'On the Service Flow from Labour', Review of Economic Studies 40 (1973), pp. $36-45$.

Demaris, A., Logit Modeling. Practical Applications (Newbury Park 1992).

DeVries, J., 'Between Purchasing Power and the World of Goods: Understanding the Household Economy in Early Modern Europe', in R. Porter and J. Brewer, eds., Consumption and the World of Goods (London 1993).

DeVries, J., 'The Industrial Revolution and the Industrious Revolution', Journal of Economic History 54 (1994).

Feinstein, C.H., 'Changes in Nominal Wages, the Cost of Living and Real Wages in the United Kingdom over Two Centuries, 1770-1990' (unpublished manuscript, All Souls College, Oxford 1994).

Feldstein, M., 'Specification of Labour Input in the Aggregate Production Function', Review of Economic Studies 34 (1967).

Freudenberger, H. and G. Cummins, 'Health, Work and Leisure before the Industrial Revolution', Explorations in Economic History 13 (1976). 
Freudenberger, H., 'Das Arbeitsjahr', in: I. Bog et al., ed., Wirtschaftliche und soziale Strukturen im sakularen Wandel. Festschrift für Wilhelm Abel zum 70. Geburtstag, Bd.2: The vorindustrielle Zeit: Außeragrarische Probleme, (Hannover 1974).

Hardy, M., Regression with Dummy Variables (Newbury Park 1993).

Harris, M., 'Introduction', in: The Old Bailey Proceedings. Parts one and two. A Listing and Guide to the the Harvester Microfilm Collection, 1714-1834 (Brighton 1984).

Hauck, W. and A. Donner, 'Wald's Test as Applied to Hypotheses in Logit Analysis', Journal of the American Statistical Association 72 (1977).

Hopkins, E., 'Working Hours and Conditions during the Industrial Revolution: A ReAppraisal', Economic History Review 35 (1982).

Jones, E., Agriculture and the Industrial Revolution (Oxford 1974).

Johnson, P. and S. Nicholas, 'Health and Welfare of Women in the United Kingdom 17851920', Paper presented to the NBER conference on health and welfare during industrialization, Cambridge, MA, April 21-22, 1995.

Juster, F. T., 'Response Errors in the Measurement of Time Use', Journal of the American Statistical Association 81 (1986).

Juster, F. T. and F. Stafford, 'The Allocation of Time: Empirical Findings, Behavioral Models, and Problems of Measurement', Journal of Economic Literature 29 (1991).

King, P., 'Pauper Inventories and the Material Lives of the Poor in the Eigtheenth and Early Nineteenth Centuries', in: T. Hitchcock, P. King and P. Sharpe, eds., Words of the Poor (London 1996).

Komlos, J., Nutrition and Economic Development in the Eighteenth Century Habsburg Monarchy (Princeton 1989).

Komlos, J.,'The Secular Trend in the Biological Standard of Living', Economic History Review 46 (1993).

Lindert, P. and J. Williamson, 'Revising England Social Tables, 1688-1913', Explorations in Economic History 19 (1982).

Maddison, A., Dynamic Forces in Capitalist Development (Oxford 1991).

Matthews, R., C. Feinstein and J. Odling-Smee, British Economic Growth 1856-1973 (Oxford 1982).

McCloskey, D., '1780-1860: A Survey', in: R. Floud, D. McCloskey, eds., The Economic History of Britain Since 1700 (second ed. Cambridge 1994).

Mokyr, J.,'The Industrial Revolution and the New Economic History', in: J. Mokyr, ed., The Economics of the Industrial Revolution (London 1985).

Mokyr, J., 'The New Economic History and the Industrial Revolution', in: J. Mokyr, ed., The British Industrial Revolution. An Economic Perspective (Boulder 1993). 
Phelps Brown, E.H., S. Browne, 'Labor Hours: Hours of Work', Encyclopedia of the Social Sciences 7 (New York 1968).

Pollard, S., 'Labour in Great Britain', in: P. Mathias, M. Postan, eds., The Cambridge Economic History of Europe, vol. VII: The Industrial Economies: Capital, Labour, and Enterprise (Cambridge 1978).

Reid, D., 'The Decline of St. Monday, 1776-1876', Past and Present 71 (1976).

Rule, J., The Experience of Labour in Eighteenth Century Industry (London 1981).

Rule, J., The Labouring Classes in Early Industrial England 1750-1850 (London and New York 1986).

Schwarz, L. D., London in the Age of Industrialization: Entrepreneurs, Labour Force, and Living Conditions, 1700-1850 (Cambridge 1992).

Schwarz, L. D., 'The Standard of Living in the Long Run: London, 1700-1860', Economic History Review 38 (1985).

Solow, R., and P. Temin, 'The Inputs for Growth', in: P. Mathias, M. Postan, The Cambridge Economic History of Europe, vol. VII, part 1 (Cambridge 1978).

Thompson, E.P., 'Time, Work-Discipline, and Industrial Capitalism', Past and Present 38 (1967). 


\title{
Discussion Papers in Economic and Social History
}

\author{
are edited by: \\ Liam Brunt \\ Nuffield College, Oxford, OX1 1NF \\ James Foreman-Peck \\ St. Antony's College, Oxford, OX2 6JF \\ Susannah Morris \\ Nuffield College, Oxford OX1 1NF \\ Avner Offer \\ Nuffield College, Oxford, OX1 1NF
}

papers may be obtained by writing to

Avner Offer, Nuffield College, Oxford, OX11NF email:avner.offer@nuffield.ox.ac.uk 